\title{
Les ateliers au sud-est de la Casa degli amorini dorati
} à Pompéi

Foulerie VI 16, 3-4 et boutique VI 16, 5

Nicolas Monteix, Enora Le Quéré, François Fouriaux, Brice Ephrem, Jonathan Devogelaere et Camille Noûs

\section{OpenEdition}

Édition électronique

URL : http://journals.openedition.org/cefr/4317

DOI : $10.4000 /$ cefr. 4317

ISSN : 2282-5703

Éditeur

École française de Rome

Référence électronique

Nicolas Monteix, Enora Le Quéré, François Fouriaux, Brice Ephrem, Jonathan Devogelaere et Camille Noûs, « Les ateliers au sud-est de la Casa degli amorini dorati à Pompéi

Foulerie VI 16, 3-4 et boutique VI 16, 5 », Chronique des activités archéologiques de l'École française de Rome [En ligne], Les cités vésuviennes, mis en ligne le 25 mai 2020, consulté le 25 mai 2020. URL : http://journals.openedition.org/cefr/4317 ; DOl : https://doi.org/10.4000/cefr.4317

Ce document a été généré automatiquement le 25 mai 2020

(c) École française de Rome 


\title{
Les ateliers au sud-est de la Casa degli amorini dorati à Pompéi Foulerie VI 16, 3-4 et boutique VI 16, 5
}

\author{
Nicolas Monteix, Enora Le Quéré, François Fouriaux, Brice Ephrem, \\ Jonathan Devogelaere et Camille Noûs
}

\section{NOTE DE L'AUTEUR}

Composition de l'équipe : Nicolas Monteix (Institut universitaire de France, GRHis EA 3831), Enora Le Quéré (Université de Rouen-Normandie / GRHis EA 3831) ; Caroline Autret (céramologue, GRHis EA 3831), Saverio De Rosa (numismate), Jonathan Devogelaere (archéologue, UMR 7299, Centre Camille-Jullian), Brice Ephrem (ichtyologue, UMR 5607, Ausonius), François Fouriaux (topographe, École française de Rome), Giacomo Casa et Rebecca Santinelli (étudiants, Sapienza Università di Roma).

\section{Avant-propos}

Nous remercions le Parco archeologico di Pompei pour nous avoir permis de travailler dans les meilleures conditions. Nous remercions tout particulièrement le prof. Massimo Osanna, directeur général du Parc, la dott.ssa Grete Stefani, directrice du site, la dott.ssa Silvia Martina Bertesago, fonctionnaire archéologue responsable de notre secteur, Vincenzo Sabini, assistant technique, Domenico Busiello et Ulderico Franco, responsables des dépôts.

Cette campagne de fouilles s'inscrit dans un projet plus large faisant partie des programmes de recherche quinquennaux de l'École française de Rome et de l'École française d'Athènes. Intitulé «Espaces urbains de production et histoire des techniques à Délos et à Pompéi» (DELPO), il vise à s'interroger sur le fonctionnement de 
l'économie urbaine antique, perçue au prisme des activités de production, en comparant le tissu productif de deux villes méditerranéennes « moyennes » de l'Empire romain, à travers l'étude des systèmes techniques et l'identification des activités de production se déroulant sur chacun des sites. La fouille a été réalisée dans le cadre d'une concession pluriannuelle (2018-2020) accordée par le Ministero per i Beni e le attività culturali ${ }^{1}$. La campagne de cette année s'est déroulée du $1^{\mathrm{er}}$ au 31 juillet 2019.

Par convention, le nord géographique est décalé de $25^{\circ}$ vers l'est. Le traitement des données stratigraphiques a été grandement facilité par l'utilisation du Stratifiant, conçu par B. Desachy. Les photogrammétries ont été réalisées en utilisant une licence Metashape fournie par la TGIR Huma-Num. Enfin, les données planimétriques ont été intégrées à un SIG développé sous QGIS. Tous les plans produits ici sont au $1 / 75$, à l'exception de la fig. 1 , au 1/100; les coupes et élévations sont au 1/20.

3 Cette seconde campagne visait à étendre le nettoyage et la fouille stratigraphique des espaces déjà explorés en 2018 (fig. 1). Si, d'une manière générale, nous renvoyons au rapport précédent pour la description des différents éléments mis au jour pendant cette première campagne, il convient de souligner que la chronologie proposée dans les pages qui suivent modifie celle avancée l'an passé.

Fig. 1 - Pompéi, VI 16, 3-4 et VI 16, 5. Nomenclature des espaces et limites des opérations de nettoyage et de fouille lors de la campagne 2019.

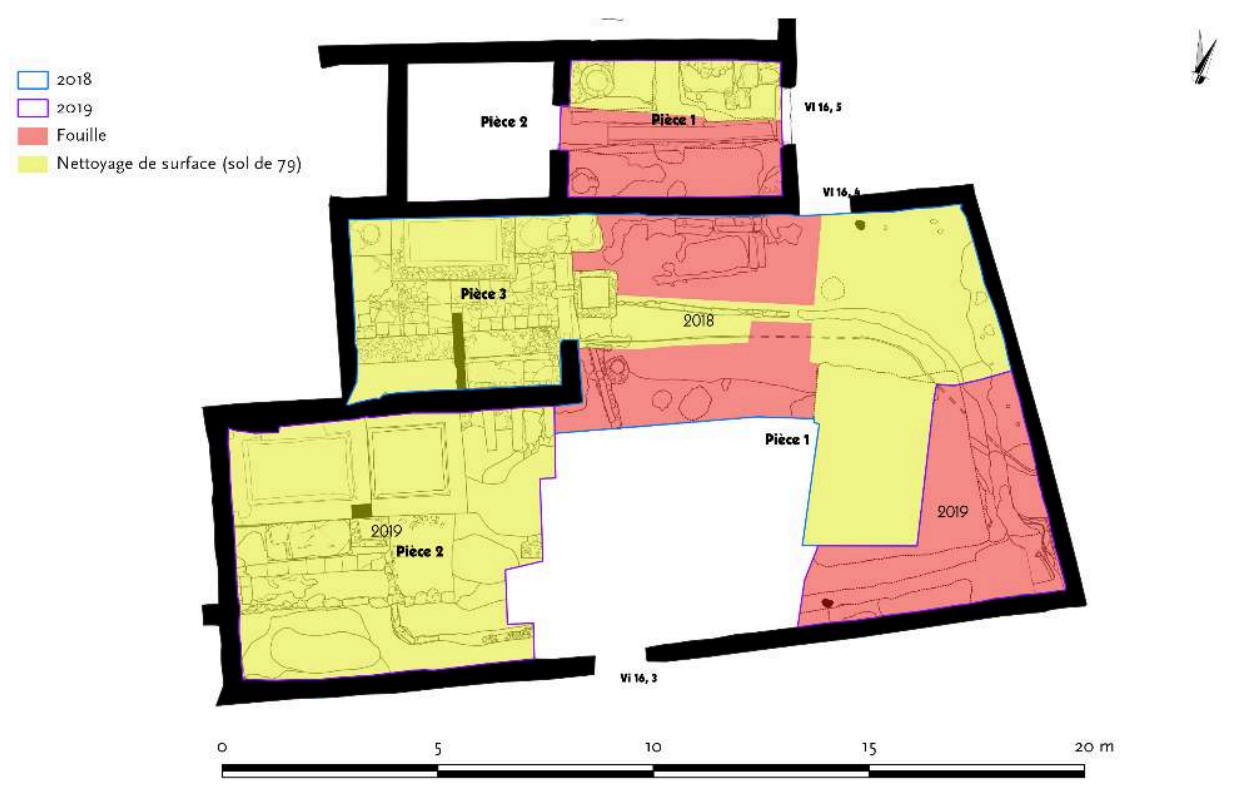

Relevé, dessin : F. Fouriaux / N. Monteix / EFR. @ CC BY-NC-SA.

\section{L'atelier VI 16, 3-4}

4 Pour mémoire, rappelons que l'atelier VI 16, 3-4 est divisé en trois espaces : au sud, la pièce 2 dans laquelle se déroulaient les opérations de foulerie ; au nord, la pièce 3 vouée au lavage des toisons; dans la moitié orientale, la pièce 1 , interprétée comme dévolue 
au filage et au tissage depuis la précédente campagne. Pour compléter les observations menées l'an passé, et en particulier pour vérifier l'extension au sud de la banquette sur laquelle auraient été installés des métiers à tisser verticaux sans peson, nous avons ouvert un sondage dans l'angle sud-est de la pièce 1. Par ailleurs, la pièce 2 a été intégralement nettoyée. Signalons enfin les nombreuses perturbations antiques immédiatement antérieures à l'éruption - et surtout modernes qui ont considérablement réduit la surface ouverte initialement (fig. 2). Outre le "bassin » (163045) de fonction indéterminée déjà observé l'an passé, la principale perturbation correspond à une fosse à chaux, presque carrée $(3,90 \times 4,10 \mathrm{~m})$, disposée à environ $1,30 \mathrm{~m}$ de l'angle sud-oriental de la pièce $1(\underline{163095}, 163096)$. Profonde de plus de $0,50 \mathrm{~m}$, elle a considérablement endommagé la stratigraphie de la pièce. Il est probable qu'elle corresponde à un espace de préparation de la chaux lors des restaurations consécutives aux bombardements survenus lors de la Seconde Guerre mondiale. De plus, le long du mur méridional de l'atelier, court, depuis l'est, un tuyau servant à l'alimentation des fontaines du site $(163140, \underline{163141})$.

Fig. 2 - Pompéi, VI 16, 3-4. Interventions modernes survenues depuis le dégagement de l'atelier.

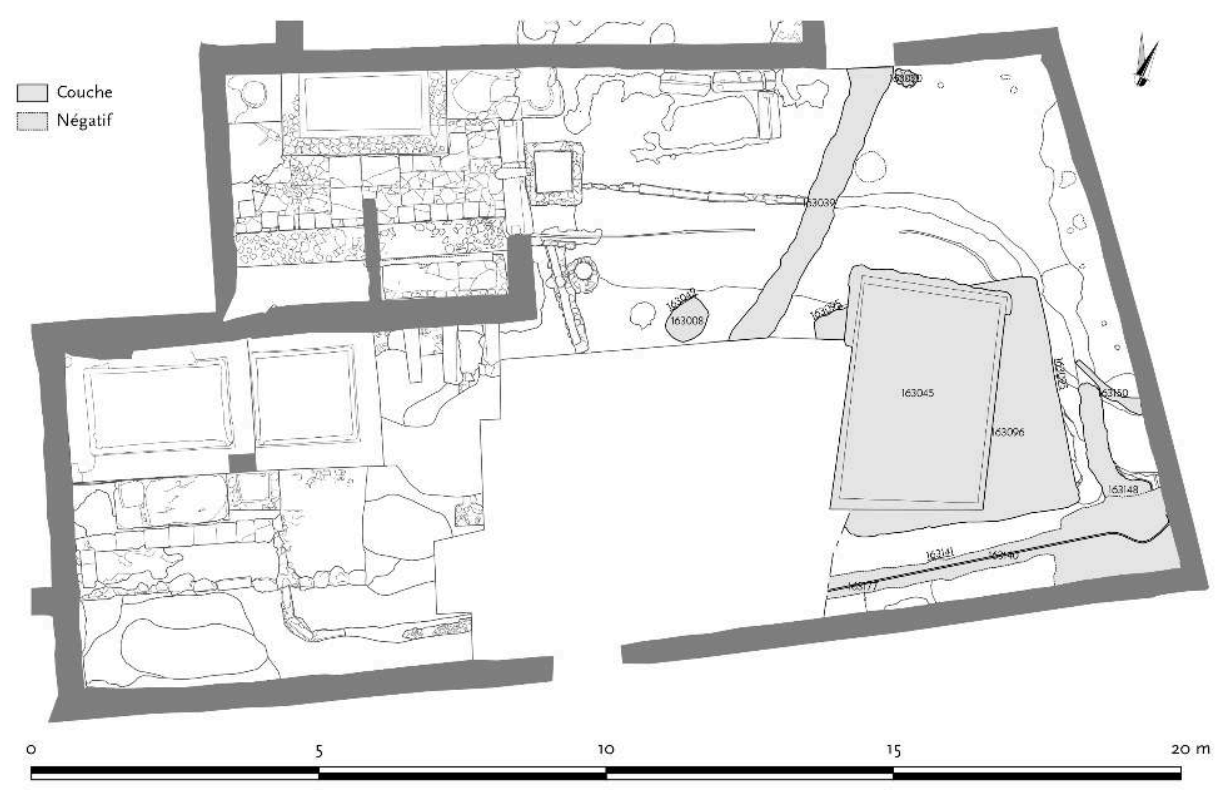

Relevé, dessin : F. Fouriaux / N. Monteix / EFR. @ CC BY-NC-SA.

\section{Niveaux éruptifs anté-pliniens}

5 De nouveau, les niveaux éruptifs anté-pliniens sur lesquels Pompéi est construite ont été observés. Comme l'an passé, ce sont les travaux de terrassement effectués au cours $d u \mathrm{I}^{\mathrm{er}} \mathrm{s}$. de $\mathrm{n}$. è. qui ont tout autant détruit une partie de la stratigraphie volcanique anté-plinienne et permis son observation. Ainsi, la fouille partielle de la grande fosse creusée dans l'angle sud-oriental de l'atelier (1632040), ensuite recreusée peu avant l'éruption de 79 (163149), a permis de mettre au jour des niveaux de grey ash (163243 et 163246 ; alt. max. : 34,59 m s.l.m.) et surtout, pour la première fois au cours de ces deux 
campagnes, les premières traces de paléosols (163244; alt. max. : 33,56 - 33,63 m s.l.m. ; fig. 3-4) ${ }^{2}$.

Fig. 3 - Pompéi, VI 16, 3-4. Niveaux éruptifs anté-pliniens retaillés par une vaste fosse probablement consécutive au séisme de 62/63.Vue de l'est.

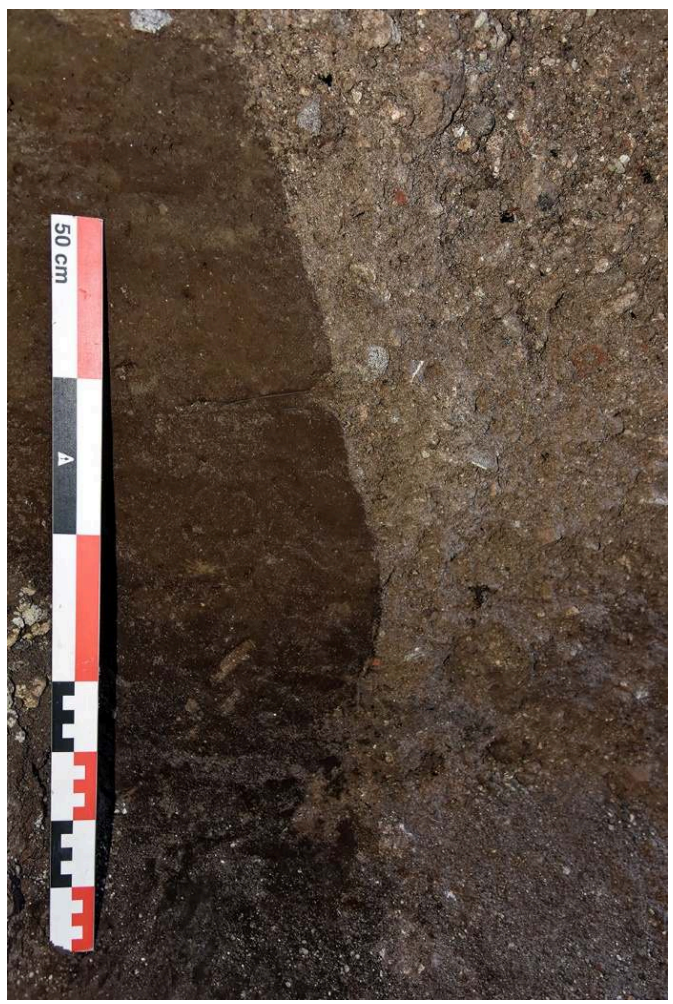

Cliché Mibac - PA Pompei / B. Ephrem / EFR. @ CC BY-NC-SA 
Fig. 4 - Pompéi, VI 16, 3-4. Coupe ouest-est immédiatement en arrière de la tranchée creusée juste avant l'éruption de 79.
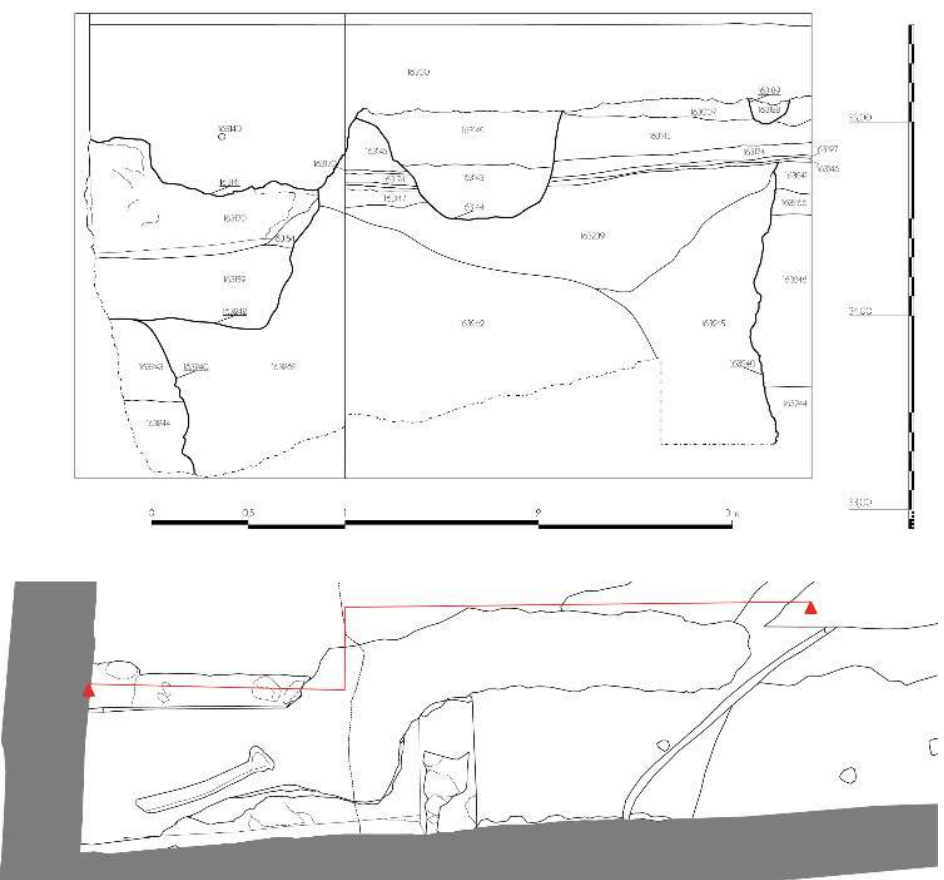

Relevé, dessin : N. Monteix / EFR. @ CC BY-NC-SA.

\section{Vestiges des phases antérieures à la seconde moitié du $\mathrm{I}^{\mathrm{er}} \mathrm{s}$. de n.è.}

Comme lors de la précédente campagne, les vestiges antérieurs à la seconde moitié du $\mathrm{I}^{\mathrm{er}} \mathrm{s}$. de $\mathrm{n}$. è. sont peu nombreux et ne peuvent que difficilement être insérés dans une trame chronologique, même relative. Au sud-est, les travaux de terrassement réalisés après le séisme de 62/63 ont irrémédiablement détruit toute stratigraphie entre les niveaux éruptifs et la reconstruction post-sismique. Au sud-ouest, il est impossible pour l'heure de mettre en relation les rares éléments épars.

7 Toutefois, signalons la mise au jour de deux bouches de citernes dans la moitié occidentale de l'atelier (fig. 5). L'une d'elles (163230), dotée d'un conduit vertical large de $0,54 \mathrm{~m}$ et haut de $0,26-0,31 \mathrm{~m}$, donne accès à une citerne, couverte par une voûte en berceau, dont la largeur restituée est de $1,25 \mathrm{~m}$. Il pourrait s'agir du pendant de la bouche observée dans la pièce 3 (163134) lors de la campagne 201833. À 3,00 m au sudouest, une seconde bouche a été observée dans la pièce 2 (163258). Son mode de construction apparait différent, à en juger par le conduit, d'un diamètre de $0,58 \mathrm{~m}$ à son sommet conservé et de 0,68 dans sa partie inférieure, 0,43 m plus bas. Faute d'avoir pu vider l'intégralité du conduit, il n'est possible de déterminer ni la forme ni l'extension de la citerne sous-jacente. 
Fig. 5 - Pompéi, VI 16, 3-4. Plan des vestiges antérieurs à la seconde moitié du $\mathrm{I}^{\mathrm{er}} \mathrm{s}$. de n.è. En bleu, les bouches de citernes mises au jour en 2018 et 2019.

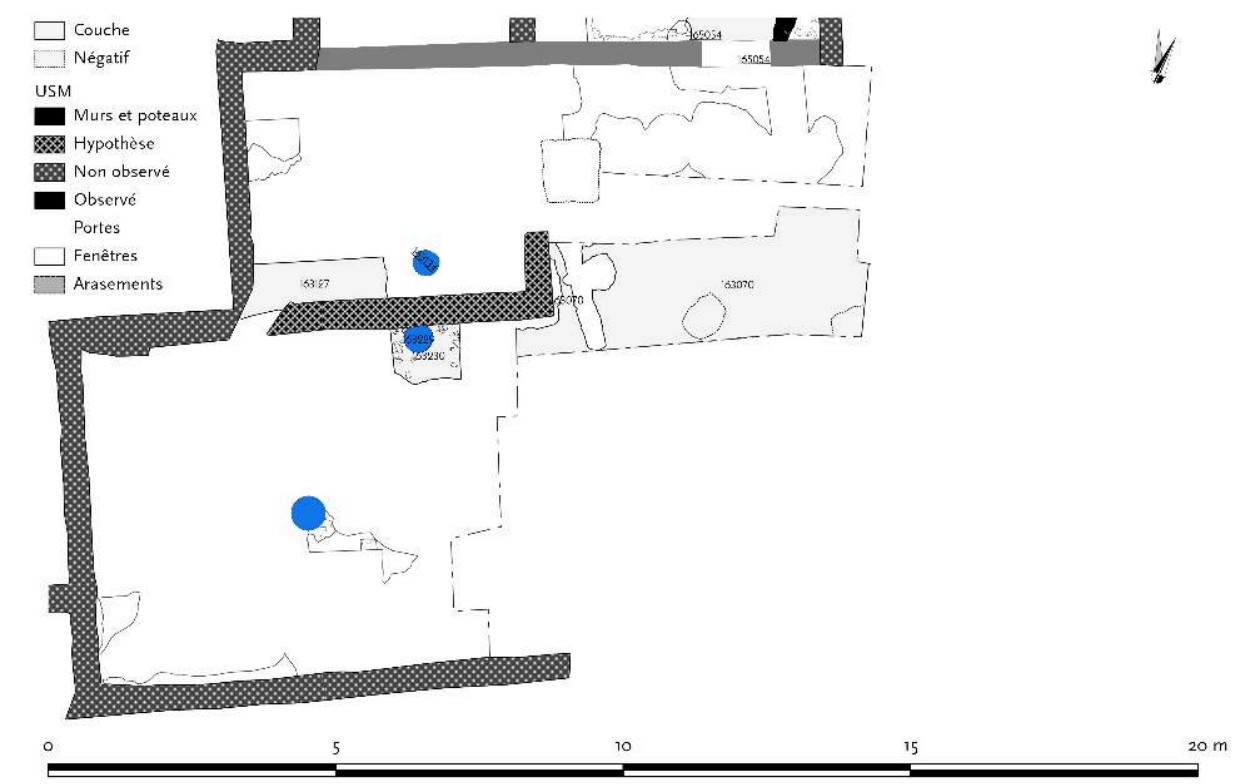

Relevé, dessin : F. Fouriaux / N. Monteix / EFR. (C) CC BY-NC-SA.

\section{Réparations successives au séisme de 62/63}

Les travaux consécutifs au séisme qui a frappé Pompéi en $62 / 63$ ont été particulièrement importants, au moins en termes de volume de terre déplacée à cette occasion (fig. 6). Le principal élément permettant de mettre en évidence ces importants travaux consiste en deux fosses ( $\underline{163238}$ et $\underline{163240}$ ) observées dans l'angle sud-est de l'atelier. Toutes deux ont largement perforé les niveaux anté-pliniens, dépourvus, à leur surface probablement déjà abaissée à ce moment, de tout vestige correspondant à l'époque archaïque ou hellénistique. Bien qu'il n'ait pas été possible de fouiller intégralement l'une ou l'autre fosse, la ligne de creusement quasiment verticale observée au nord et au sud (fig. 3, 4 et 7) de la fosse $\underline{163240}$ laisse présumer une profondeur beaucoup plus importante que les $1,40 \mathrm{~m}$ observés. Longue de $3,50 \mathrm{~m}$ et large d'au moins $2,20 \mathrm{~m}$, cette fosse visait très certainement à prélever dans le sous-sol les sables éruptifs déposés après l'éruption du Mercato pour les exploiter dans le cadre de la reconstruction des bâtiments. Ces fosses ont été rebouchées presque exclusivement avec des gravats et des décombres - blocs, moellons, enduits peints. Le pendage et les éléments constitutifs des trois couches de comblement observées $(163239,163245,163262)$ permettent de restituer un remplissage progressif depuis le sud-ouest, générant une concentration des éléments de plus gros modules contre les parois septentrionale et orientale de la fosse. 
Fig. 6 - Pompéi, VI 16, 3-4. Plan des éléments mis en place lors des restaurations consécutives au séisme de $62 / 63$.

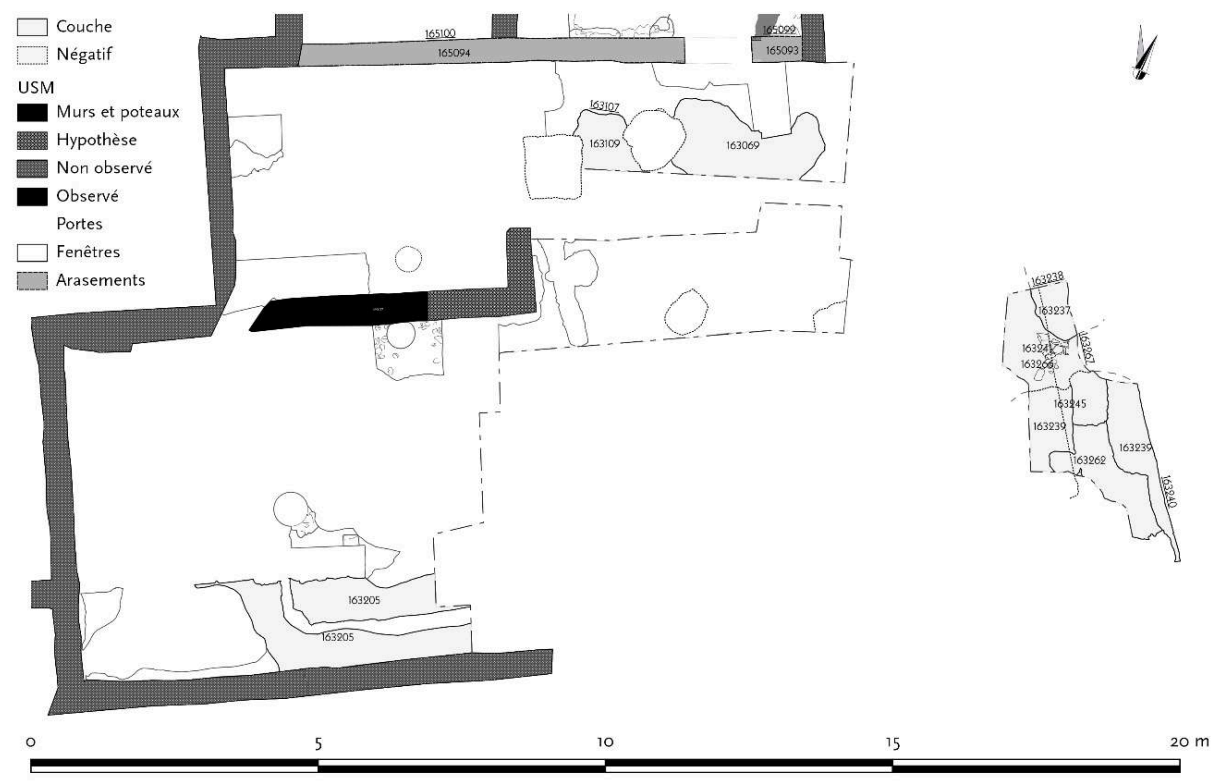

Relevé, dessin : F. Fouriaux / N. Monteix / EFR. @ CC BY-NC-SA.

Fig. 7 - Pompéi, VI 16, 3-4, pièce 1. Fosse 163040, creusée après le séisme de $62 / 63$ pour extraire du matériel éruptif, en cours de fouille. Vue de l'ouest.

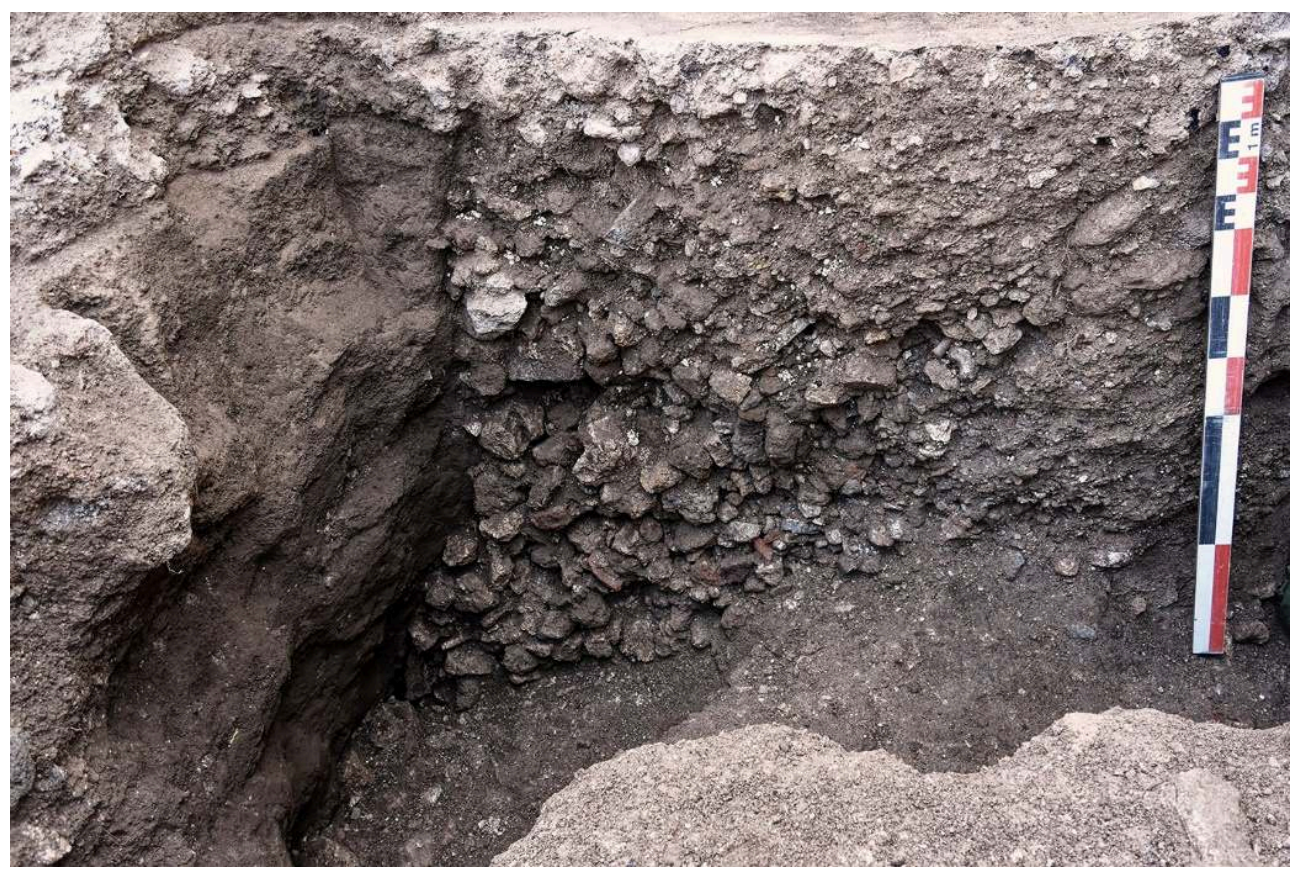

Cliché Mibac - PA Pompei / B. Ephrem / EFR. @ CC BY-NC-SA.

9 L'absence de tout élément s'intercalant entre les niveaux éruptifs anté-pliniens et ces fosses $^{4}$ permet de se poser la question de la forme de l'îlot VI 16 avant le séisme de 62/63. En effet, aucun mur périmétrique antérieur n'a été observé. Les murs fermant 
l'atelier au sud-est sont directement coulés dans les niveaux éruptifs anté-pliniens, tout en recoupant le comblement de la fosse. À tout le moins, ces murs sont postérieurs aux réparations effectuées après le séisme de $62 / 63$. Peut-être constituent-ils une extension de l'îlot survenue à la faveur de cette catastrophe.

Dans le reste de l'atelier, outre les éléments détaillés dans le précédent rapport, on soulignera simplement le fait que la disposition des pièces a été, dans la partie occidentale, restaurée à l'identique, en particulier les pièces 2 et 3 dont le mur diviseur a été reconstruit en laissant un accès de l'une à l'autre. De plus, nous y reviendrons plus bas, la liaison entre la boutique VI 16, 5 et la partie septentrionale de VI 16, 3-4 est également maintenue.

\section{Première phase de l'atelier}

11 Pour les phases consécutives au séisme de 62/63, qui correspondent à la mise en place et au développement de l'atelier en VI 16,3-4, nous avons opté pour une chronologie détaillée - essentiellement relative, faute de matériel permettant des datations précises sur un arc de temps aussi court -, qui autorise à suivre dans le détail la mise en place progressive des différents aménagements de production.

12 Après une première phase de restauration à l'identique, de profondes transformations sont mises en œuvre (fig. 8). En premier lieu, un mur périmétrique définit une (nouvelle?) emprise pour l'espace VI 16,3-4, qui ne subira ensuite aucune variation jusqu'à l'éruption de 79. Au moins deux portes sont ménagées pour accéder dans cet espace, l'une correspondant à l'entrée 4, restée ensuite inchangée, et une seconde porte en vis-à-vis de la première sur le côté sud de l'îlot, l'entrée 3bis ${ }^{5}$.

Fig. 8 - Pompéi, VI 16, 3-4. Plan des transformations survenues lors de l'installation de l'atelier, après le séisme de 62/63.

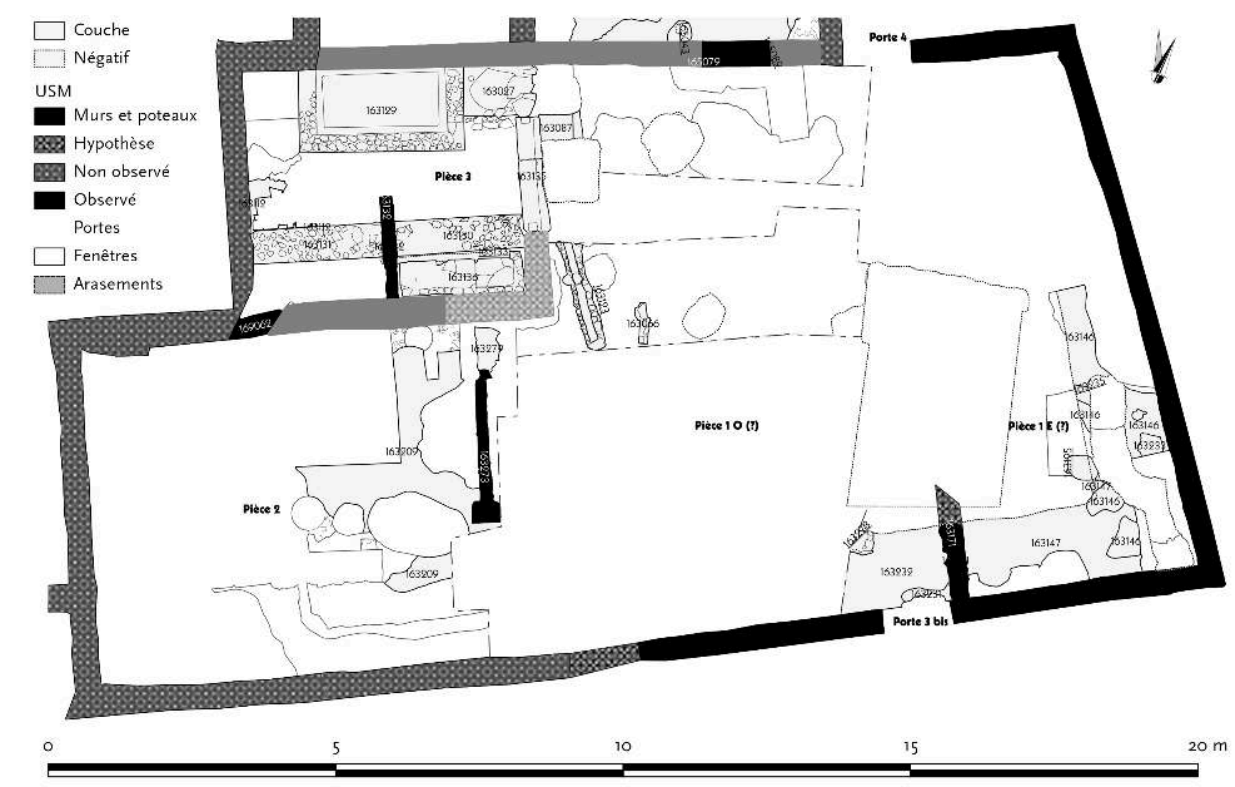

Relevé, dessin : F. Fouriaux / N. Monteix / EFR. @ CC BY-NC-SA. 
$\mathrm{Au}$ moins quatre pièces sont alors définies. La pièce 1 est a minima divisée en deux espaces (10 et 1E), de part et d'autre d'un mur nord-sud (163171) partant du montant oriental de la porte 3bis (fig. 9). La pièce 2 est réduite d'environ un mètre dans le sens est-ouest par rapport à ses dimensions finales. Un mur de refend nord-sud (163273) la sépare de la pièce 10 . On accède probablement à cette pièce 2 par deux portes, l'une située au nord, la seconde au sud, cette dernière étant marquée par un pilier. Enfin, la pièce 3 devient uniquement accessible par l'est, la porte permettant la communication avec la pièce 2 étant probablement bouchée (169062).

Fig. 9 - Pompéi, VI 16, 3-4, pièce 10. Le mur de refend nord-sud (163171) divisant la pièce 1 en deux espaces distincts. Vue du nord.

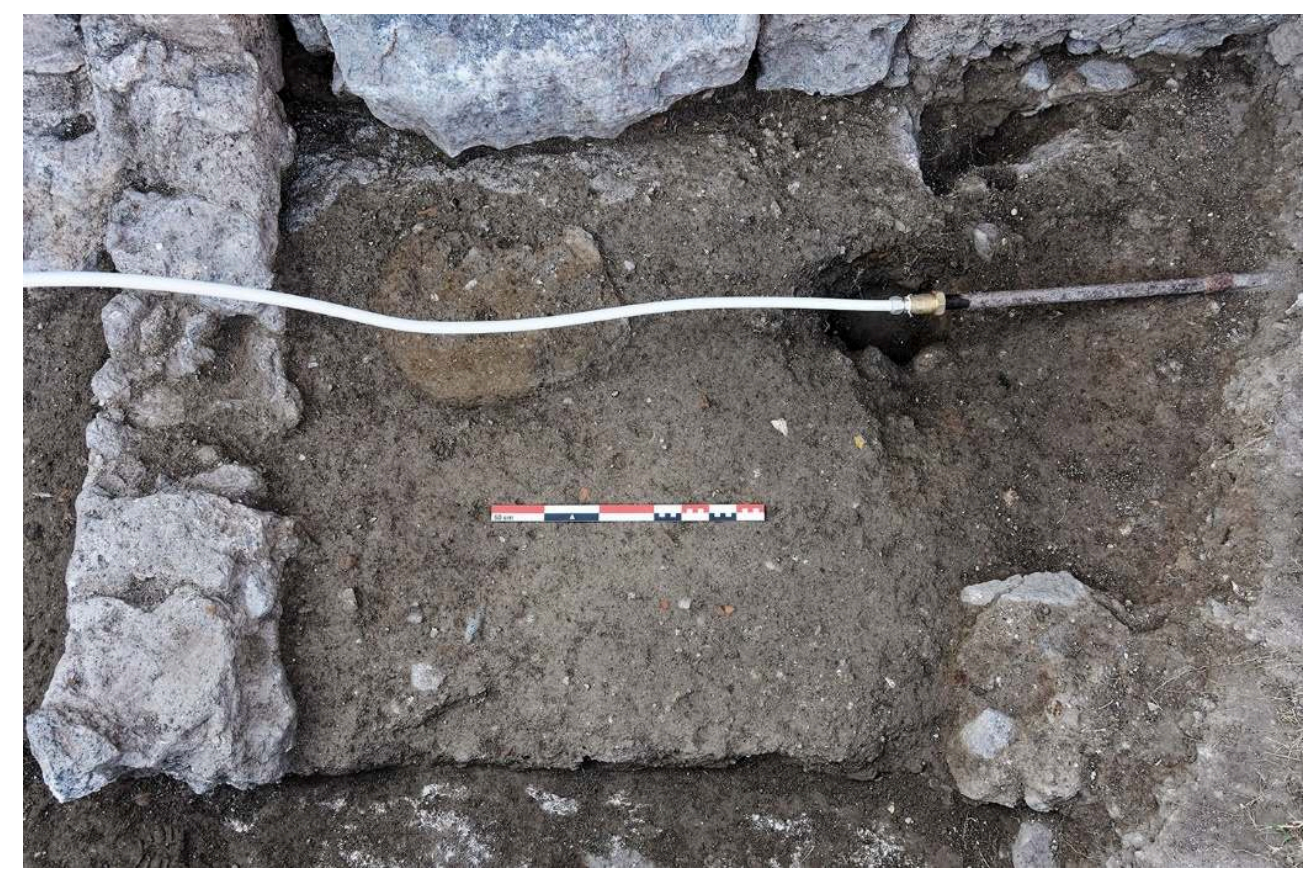

Cliché Mibac - PA Pompei / B. Ephrem / EFR. @ CC BY-NC-SA.

Le premier état de cette première phase correspond à l'installation de l'atelier, ou, à tout le moins, d'une partie de celui-ci. A minima, une laverie de toisons est installée dans la pièce 3 , avec une morphologie qui ne changera que peu au fil du temps : seule la chaudière 163027 finira par être déplacée de l'angle nord-est à l'angle nord-ouest de la pièce. La canalisation d'évacuation des eaux usées (163015) traverse la pièce 10 du nord au sud et il est probable que le réseau d'adduction d'eau ait également traversé cette même pièce (cf. infra, fig. 42) ${ }^{6}$. Un seul autre aménagement est timidement apparu dans cette salle : au sud, une portion de mur (163236) a été mise au jour. Il faudra attendre la prochaine campagne pour comprendre son extension et sa destination.

Dans la pièce 1E, un fin sol de béton, assez simple, quoique parfois rehaussé d'éclats de céramiques, et de facture assez modeste, sert de sol dans un premier état de fonctionnement (163146, fig. 10). À l'usage, il a rapidement cessé d'être entretenu et a permis la formation de niveaux de terre battue. Dans la fenêtre réduite à travers laquelle ce premier état de la pièce a été observé, aucun autre aménagement ne permet de déterminer la nature des activités s'y déroulant. 
Fig. 10 - Pompéi, VI 16, 3-4, pièce 1E. Niveau de sol de béton (163146) dans la pièce 1E. Vue de l'ouest.

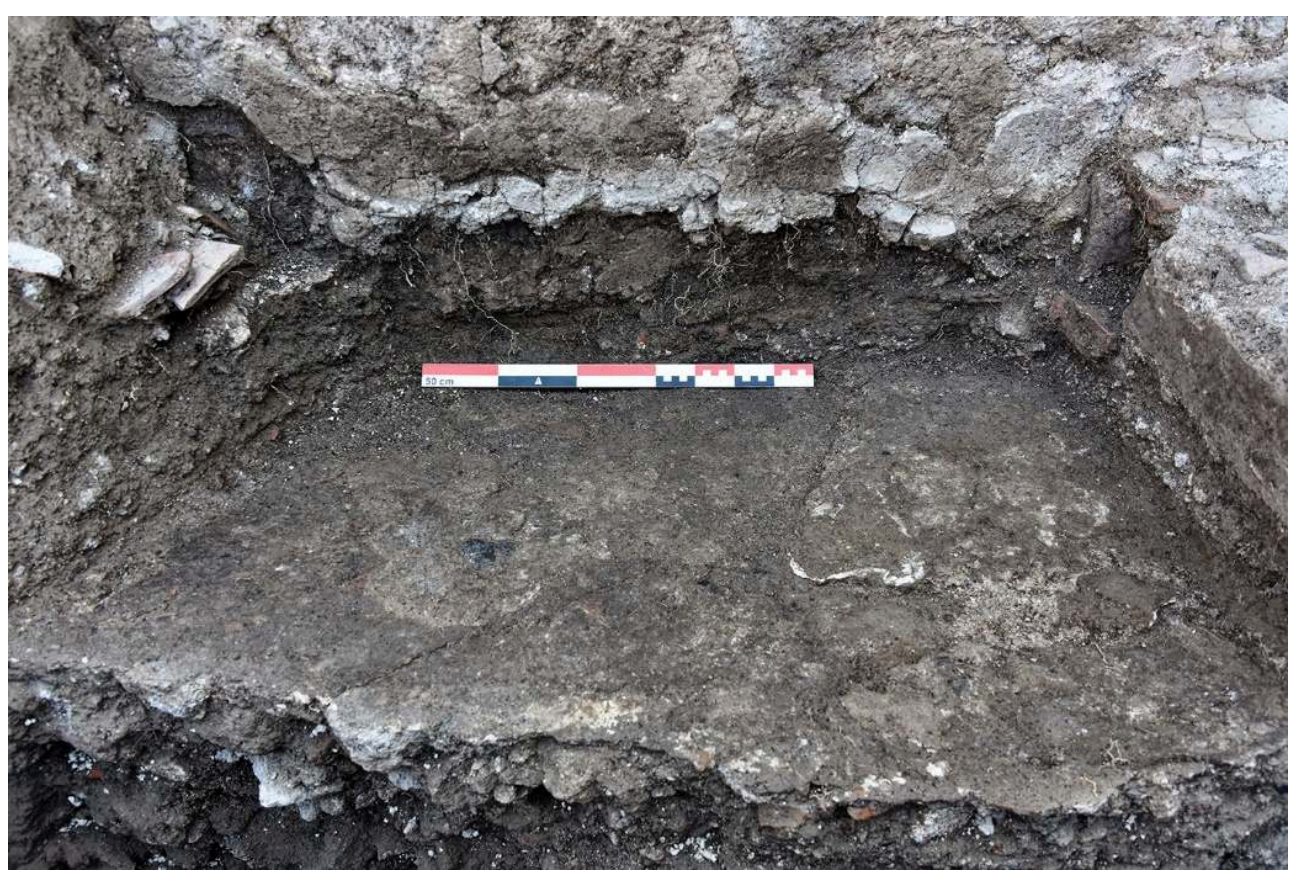

Cliché Mibac - PA Pompei / B. Ephrem / EFR. @ CC BY-NC-SA.

16 Dans la pièce 2, le principal changement touche la citerne 163230, désormais condamnée, comme son possible pendant dans la pièce 3 . En revanche, la citerne 163258 paraît avoir continué d'être utilisée. Le sol de cette pièce est un niveau de terre battue (163209), peu fréquenté (fig. 11). Pour l'heure, aucun autre élément ne permet de déterminer les fonctions exercées dans cette pièce ${ }^{7}$. 
Fig. 11 - Pompéi, VI 16, 3-4, pièce 2. Niveau de circulation mis en place lors des premières transformations consécutives au séisme de $62 / 63$ et maintien en usage de la citerne 163258 . Vue de l'ouest.

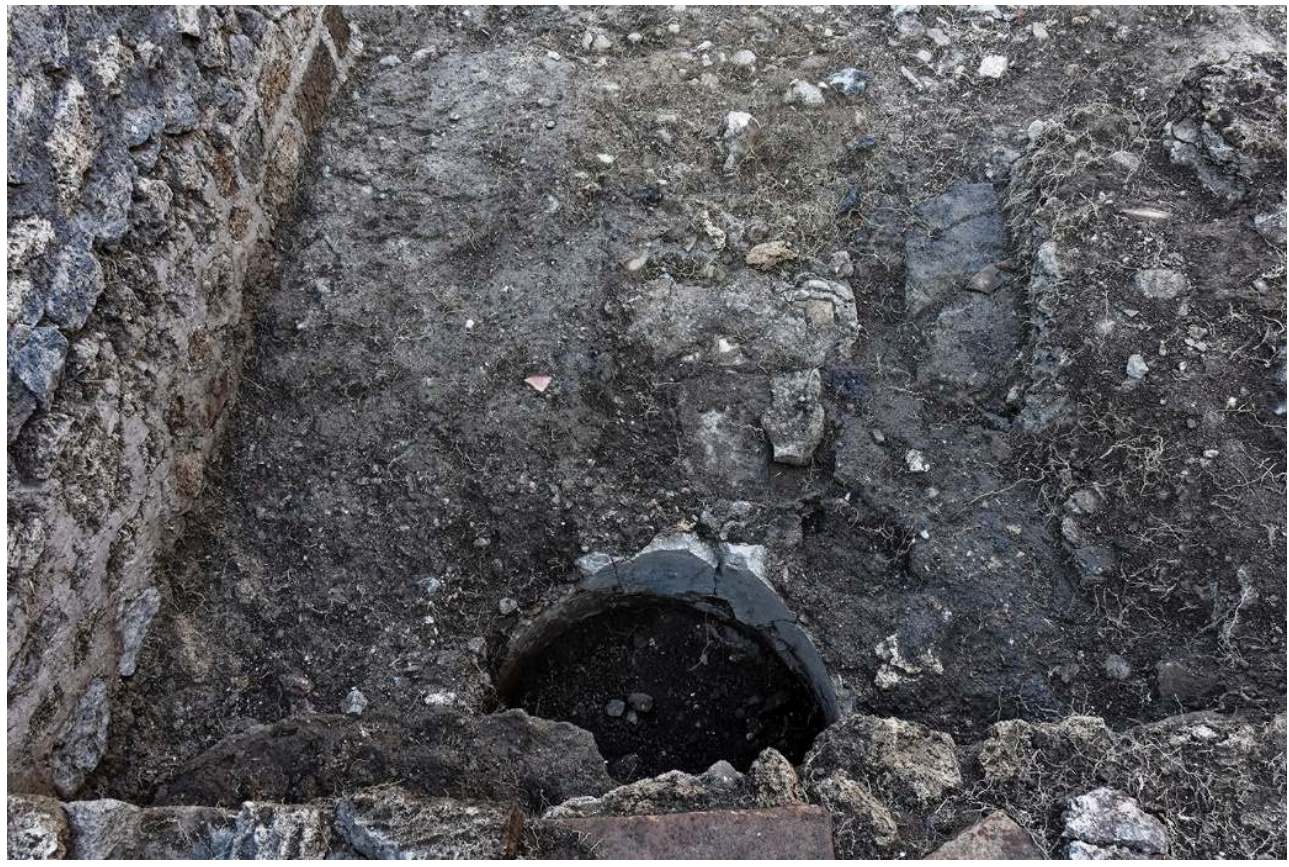

Cliché Mibac - PA Pompei / F. Fouriaux / EFR. @ CC BY-NC-SA.

17 Le second état de cette première phase se caractérise, dans la pièce 10, par des variations dans les implantations de production liées au lavage des toisons : un bassin de décantation (163016) est ajouté le long de la canalisation d'évacuation des eaux (fig. 12) ${ }^{8}$. Dans la pièce $1 \mathrm{E}$, des travaux plus conséquents sont réalisés. Un bassin maçonné, long de $1,77 \mathrm{~m}$ et large de $0,73 \mathrm{~m}$, d'une contenance utile maximale de $420 \mathrm{~L}$, est installé dans l'angle sud-est de la pièce (163154, fig. 4, 13-15). Les forts dommages subis pendant la période moderne empêchent de déterminer son mode de vidange. Puissamment fondé et revêtu d'un résistant enduit de mortier hydraulique, il présente, retaillée dans son bord septentrional, une encoche probablement liée à un système d'adduction. Un second aménagement hydraulique, de nature plus complexe à déterminer, a été construit dans l'angle sud-ouest de la pièce $1 \mathrm{E}$. Il s'agit d'une maçonnerie rectangulaire, longue de 1,26 m, large de 0,39 m et conservée sur $0,20 \mathrm{~m}$ de haut. Elle ne présente pas de bords conservés, car elle a été fortement endommagée dans les phases successives, mais, sur le mur sud, un enduit hydraulique est conservé sur $0,22 \mathrm{~m}$. En son centre, elle est concave et sa surface couverte de béton hydraulique présente un pendage du nord au sud. Un orifice d'évacuation est situé dans son angle sud-ouest (fig. 16-17). Les niveaux de sol fonctionnant avec ces aménagements sont systématiquement en terre battue. 
Fig. 12 - Pompéi, VI 16, 3-4. Plan du second état de transformations survenues après l'installation de l'atelier.

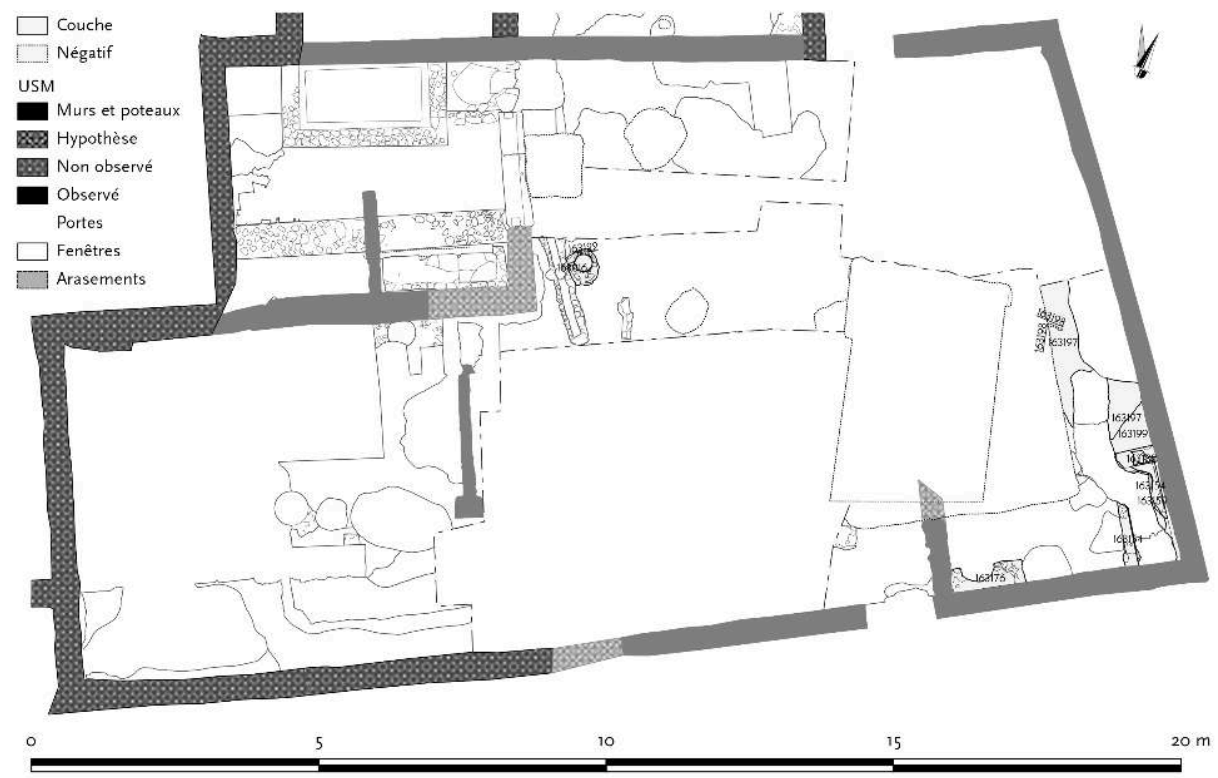

Relevé, dessin : F. Fouriaux / N. Monteix / EFR. @ CC BY-NC-SA.

Fig. 13 - Pompéi, VI 16, 3-4, pièce 1E. Bassin (163154) installé dans l'angle sud-est de la pièce 1 en. Vue de l'ouest.

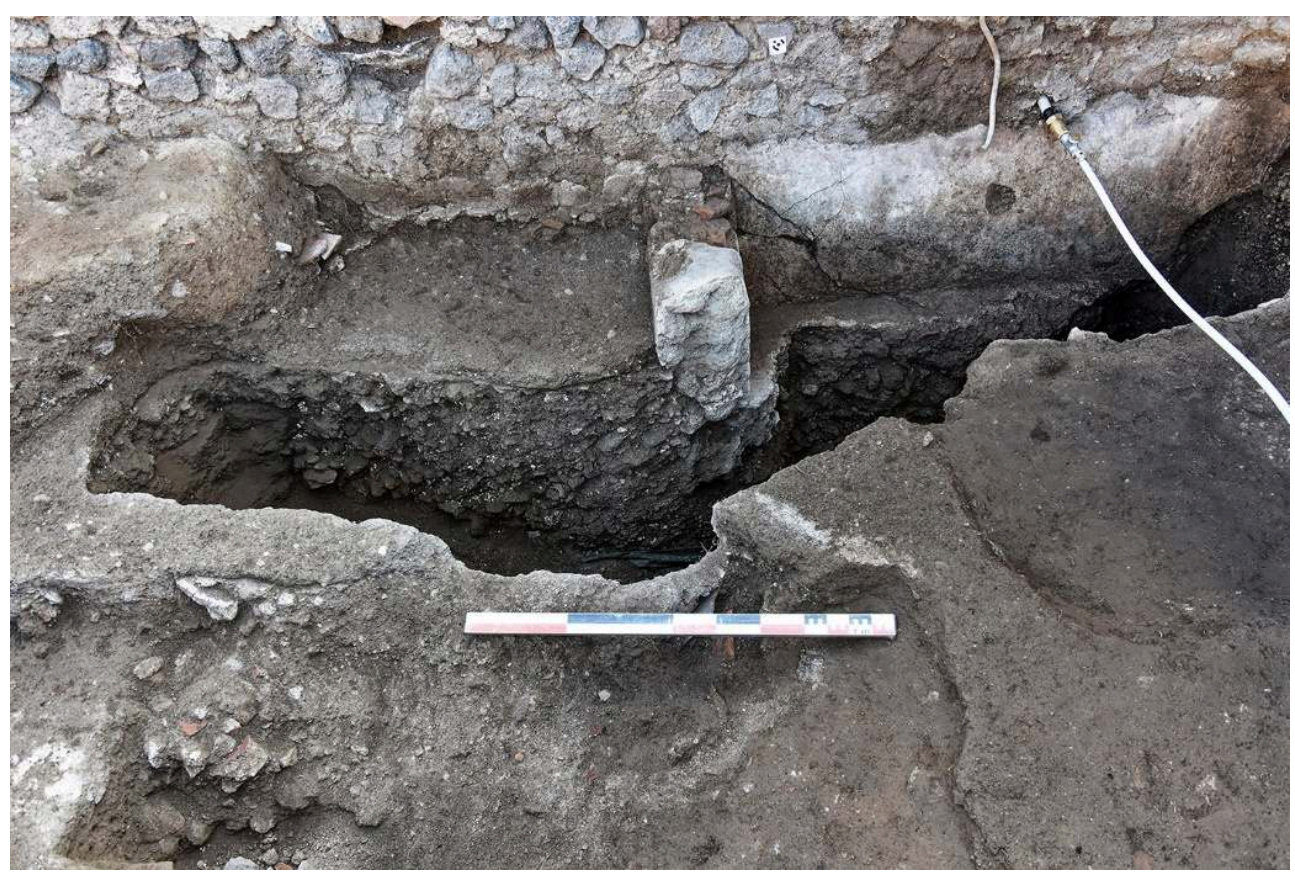

Cliché Mibac - PA Pompei / B. Ephrem / EFR. @ CC BY-NC-SA. 
Fig. 14 - Pompéi, VI 16, 3-4, pièce 1E. Bassin (163154) vu de dessus. Son fond a été perforé par une tranchée creusée peu avant l'éruption pour installer un tuyau en plomb d'adduction en eau.

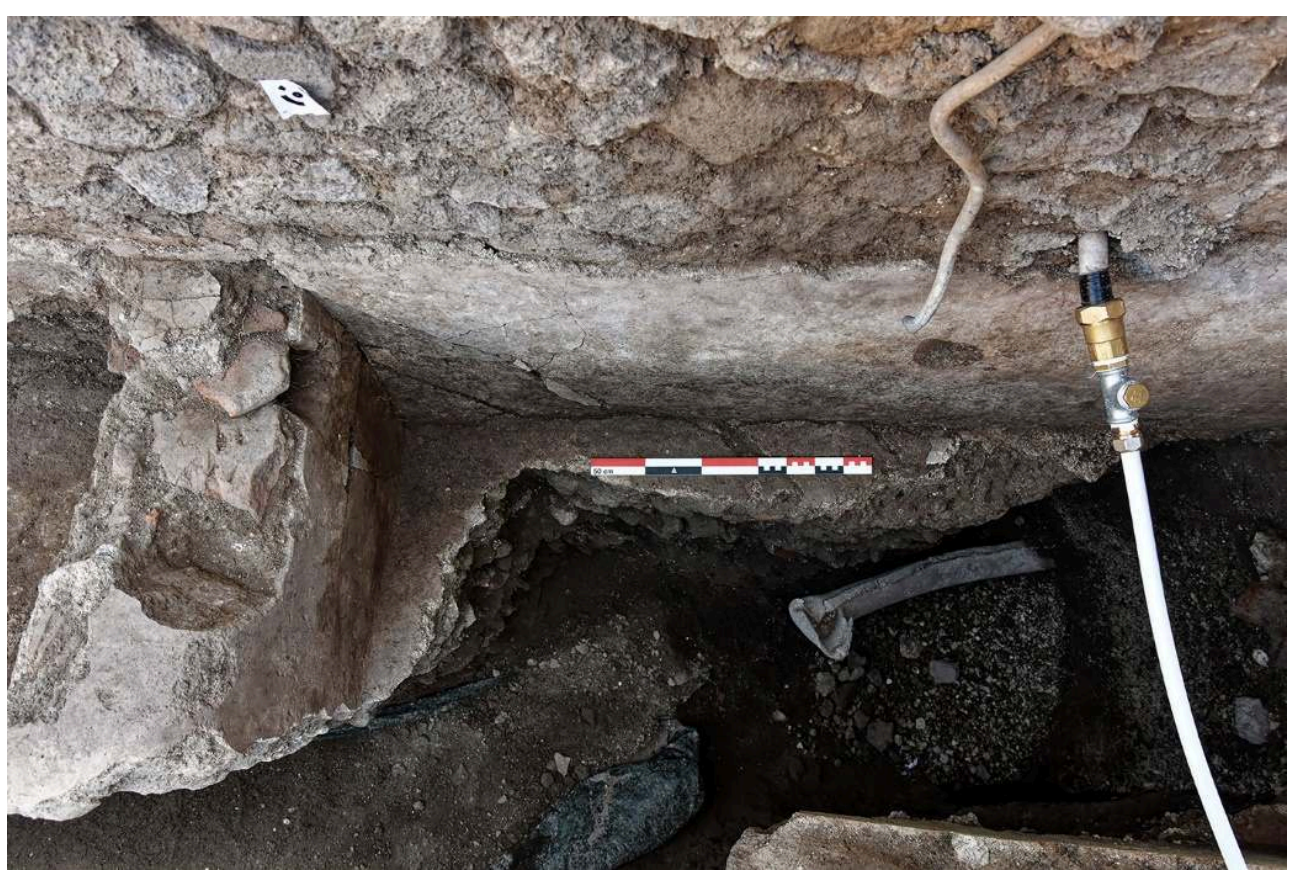

Cliché Mibac - PA Pompei / B. Ephrem / EFR. @ CC BY-NC-SA.

Fig. 15 - Pompéi, VI 16, 3-4, pièce 1E. Orifice de remplissage du bassin (163154). Vue du sud.

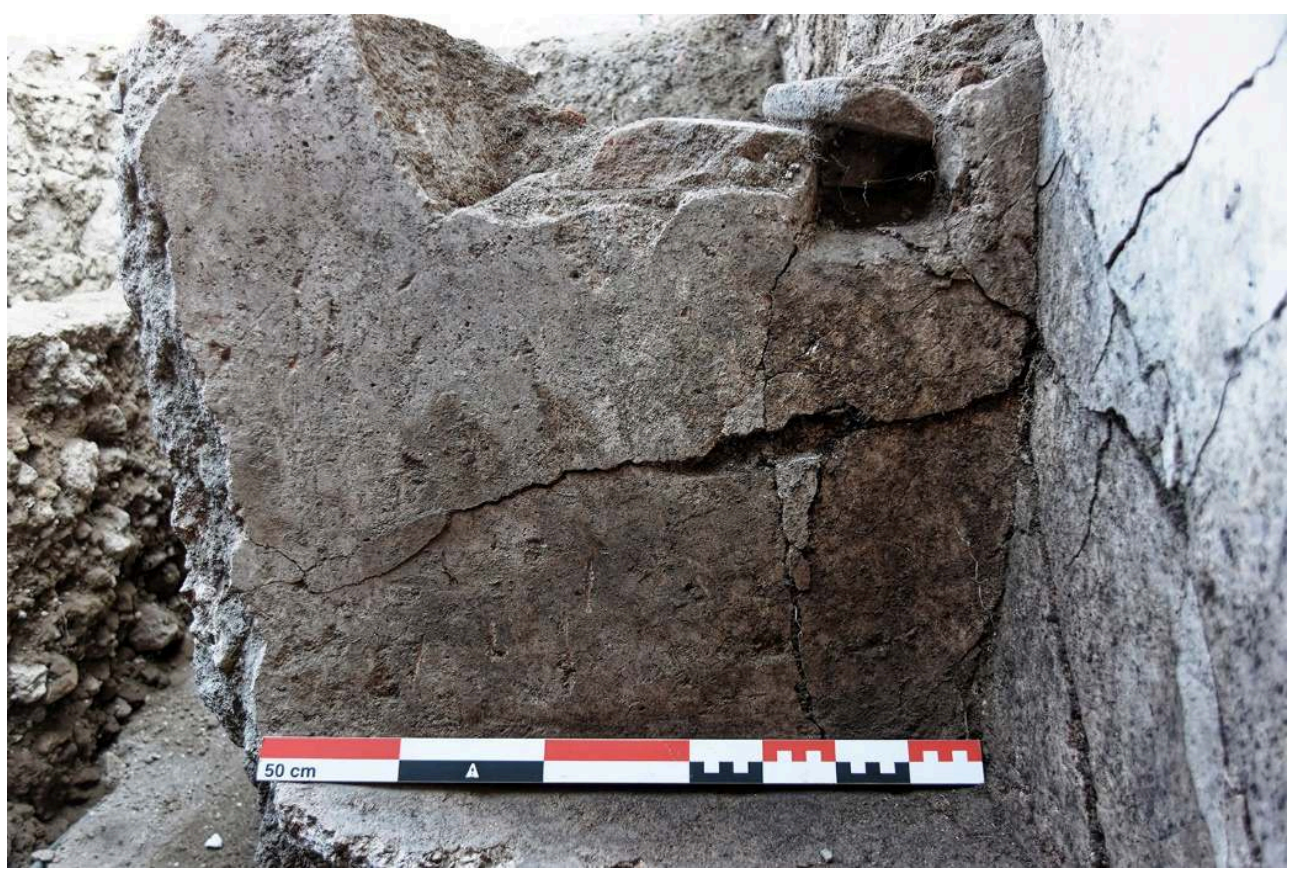

Cliché Mibac - PA Pompei / B. Ephrem / EFR. @ C CC BY-NC-SA. 
Fig. 16 - Pompéi, VI 16, 3-4, pièce 1E. Avaloir maçonné (163176) construit contre le mur sud de la pièce. Vue du nord.

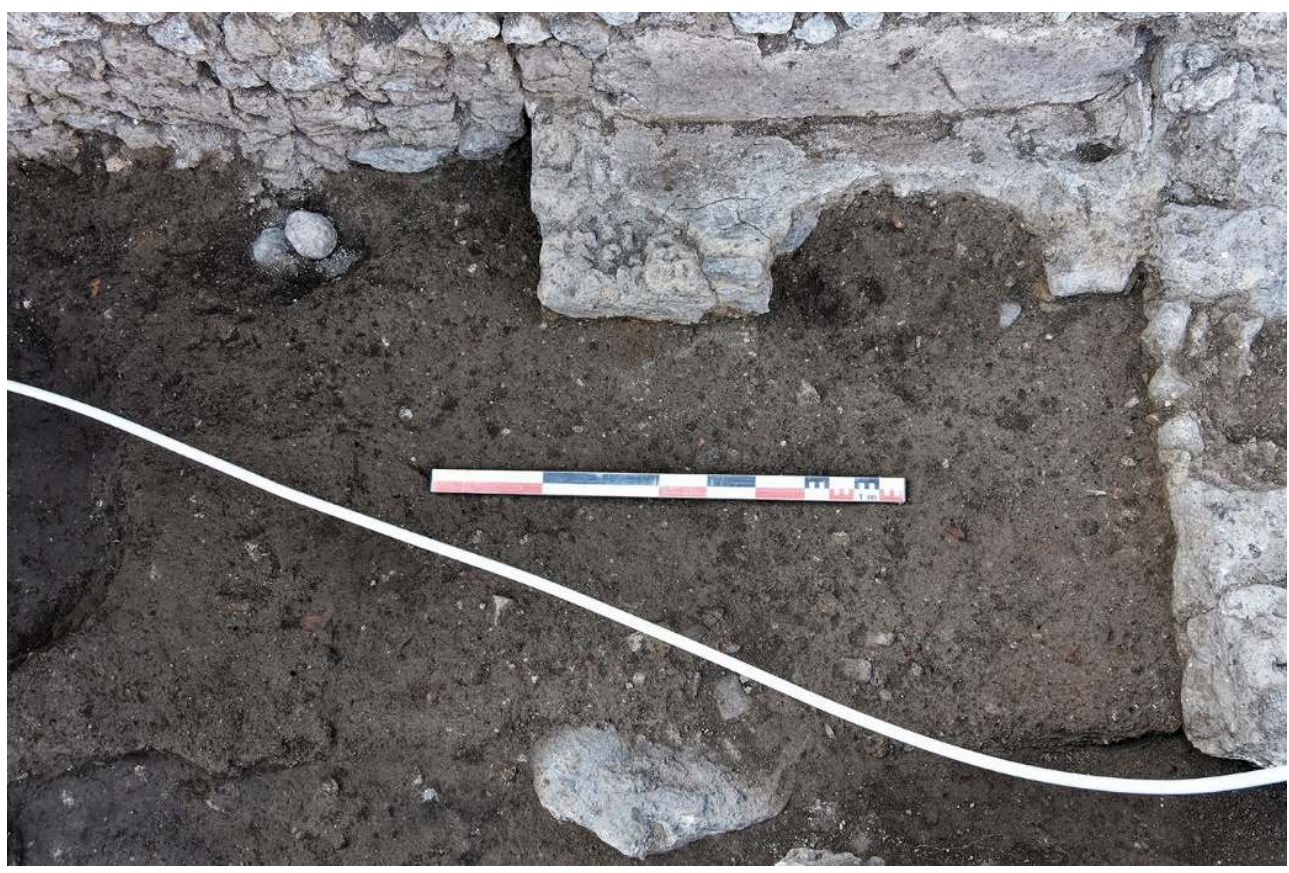

Cliché Mibac - PA Pompei / B. Ephrem / EFR. @ CC BY-NC-SA.

Fig. 17 - Pompéi, VI 16, 3-4, pièce 1E. Avaloir maçonné (163176) : détail de l'orifice de vidange. Vue du nord.

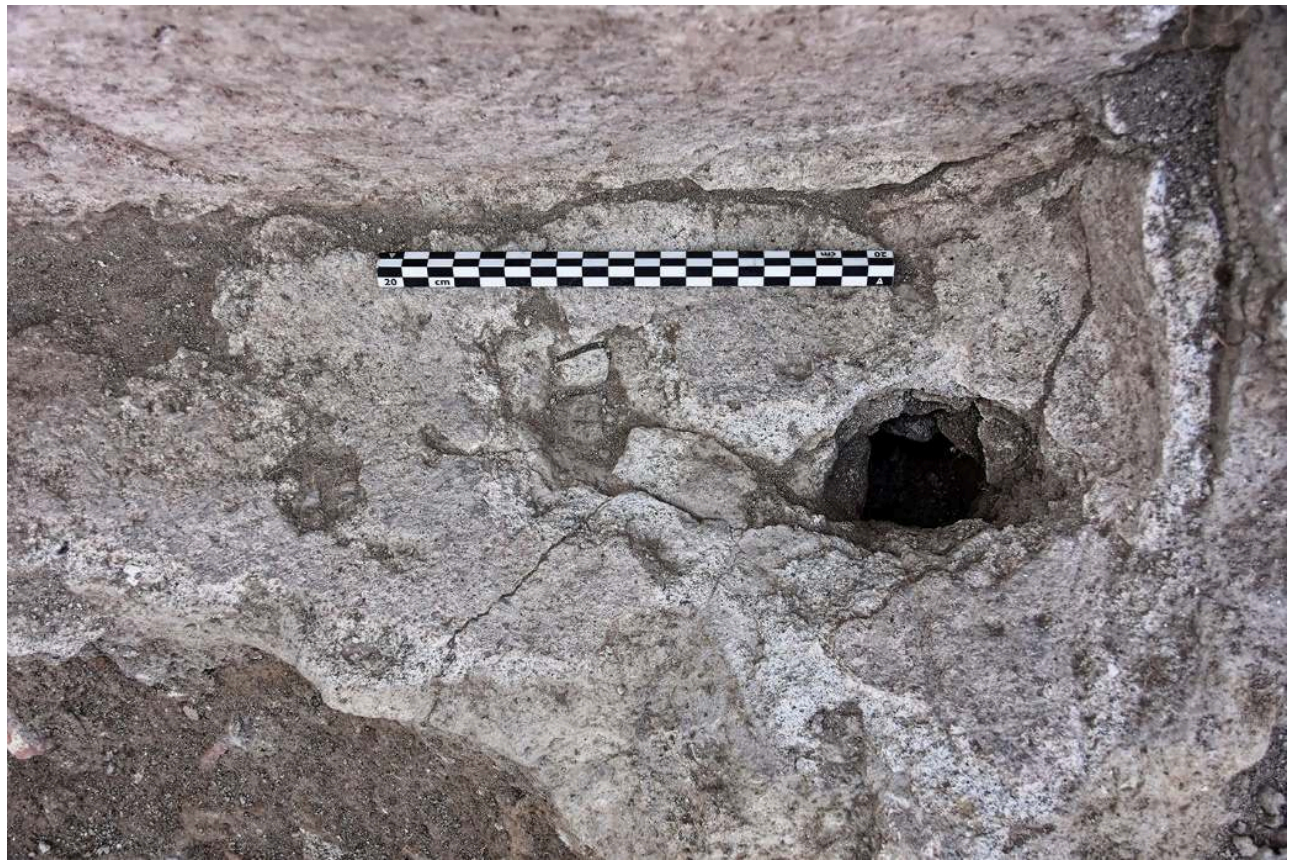

Cliché Mibac - PA Pompei / B. Ephrem / EFR. @ CC BY-NC-SA.

Si l'installation concomitante de ces deux aménagements ne fait pas de doute, leur utilisation dans le cadre d'une production textile, quelle qu'elle fut, reste pour l'instant plus problématique. En effet, le bassin est surdimensionné pour une laverie de "première génération ${ }^{9}$; il ferait de toute façon double emploi en raison de la 
présence d'un bassin de $1300 \mathrm{~L}$ dans la pièce 3. Dans les teintureries, les aménagements recevant des liquides sont des chaudières. À l'autre extrémité de la chaîne opératoire, ce bassin est trop petit par rapport à tous ceux qui sont conservés dans les autres fouleries de la ville. Enfin, l'inconnue quant à son mode de vidange, voire l'idée d'une vidange manuelle grâce à l'avaloir maçonné, laissent entrapercevoir un flottement technique assez étonnant. Peut-être ces structures ne sont-elles pas à rapprocher de la production textile?

\section{Seconde phase de l'atelier : extension de la production textile}

La seconde phase de l'atelier commence par des réparations liées à un probable second séisme (fig. 18). Les traces de ce dernier ne sont pas toujours claires ; cependant, il semble possible au moins de compter au nombre de celles-ci la réfection de l'angle sudest de la pièce 3 (169058) ainsi que la fermeture de la porte 3 bis. Au même moment, outre la possible ouverture de la porte 3 , des reprises de maçonnerie ont lieu dans la paroi méridionale donnant sur le vicolo di Mercurio. À l'intérieur, diverses modifications surviennent. Tout d'abord, le mur séparant les pièces 10 et $1 \mathrm{E}$ est arasé. Un niveau de remblai (163174) vient notamment recouvrir les aménagements hydrauliques auparavant situés dans l'angle sud-est de la pièce $1 \mathrm{E}$. Diverses fosses de nature non précisée sont creusées, soit dans la partie méridionale de la pièce 1 ( $\underline{163164}, \underline{163162}$, $\underline{163180})$, soit dans sa partie septentrionale $(\underline{163060}, \underline{163062}, \underline{163023})^{10}$.

Fig. 18 - Pompéi, VI 16, 3-4. Plan des réparations effectuées après un possible second séisme.

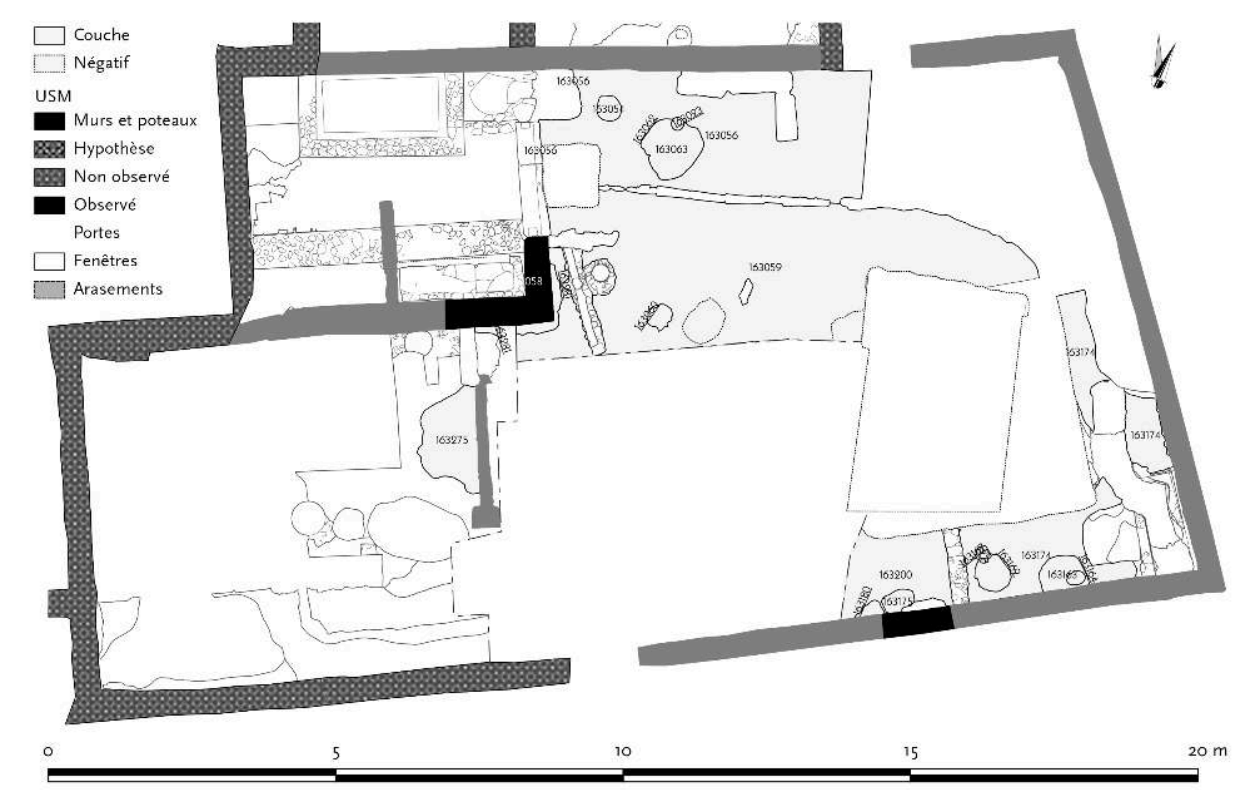

Relevé, dessin : F. Fouriaux / N. Monteix / EFR. (C) CC BY-NC-SA.

Une fois ces travaux achevés, l'atelier est profondément remodelé (fig. 19). Nous ne reviendrons pas sur les changements survenus dans la pièce 3 et dans la partie nordoccidentale de la pièce 1 , déjà évoqués dans le rapport précédent ${ }^{11}$. Une seule variation semble devoir être notée: les espaces de travail et le bassin paraissent désormais 
remonter à la première phase de l'atelier. Seul le sol de briques et de tuiles aura partiellement été refait pour permettre le passage de l'adduction en eau, en lien avec le déplacement de la chaudière de l'angle nord-est de la pièce 3 à son angle nord-ouest.

Fig. 19 - Pompéi, VI 16, 3-4. Plan de la seconde phase de l'atelier.

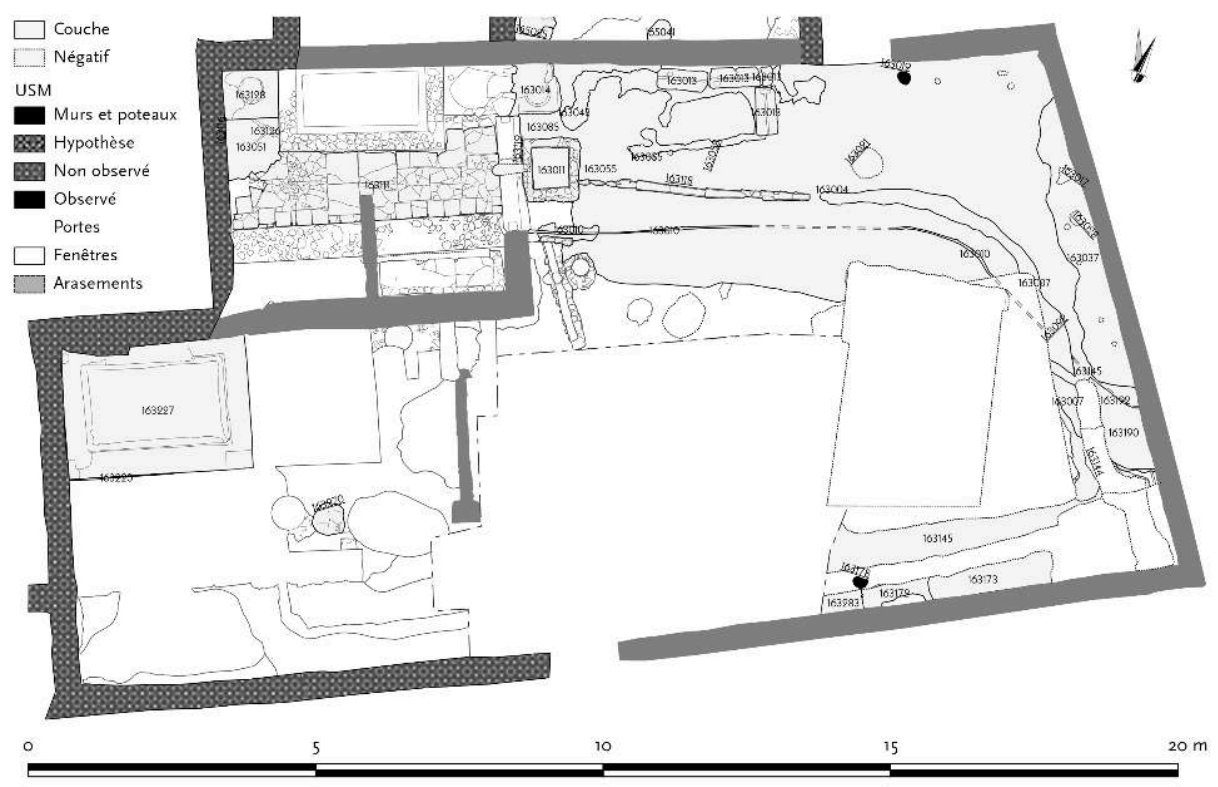

Relevé, dessin : F. Fouriaux / N. Monteix / EFR. C CC BY-NC-SA.

Dans la partie orientale de la pièce 1 , les travaux menés cette année ont permis de mettre en évidence la continuité de la banquette 163037 vers le sud. Sur la surface de celle-ci, deux nouveaux trous, pouvant être assimilés à des "poteaux " permettant l'insertion de métiers à tisser verticaux à deux ensouples, ont été mis en évidence. L'un (163184) et l'autre (163186) ont un diamètre de $0,08 \mathrm{~m}$ et une profondeur de $0,05 \mathrm{~m}$. On pourrait ainsi avoir non pas trois métiers comme cela avait été proposé l'an dernier, mais deux : l'un, long de 1,20 m contre le mur septentrional ; l'autre, long de $1,70 \mathrm{~m}$ dans un premier temps, puis de $1,52 \mathrm{~m}$ après un décalage plus au sud. Les travaux de peu antérieurs à l'éruption puis modernes ont complètement détruit l'éventuelle continuation vers le sud de la banquette sur laquelle ces métiers à tisser étaient installés. Sur le côté méridional, comme sur le côté septentrional, aucune trace de celleci n'a été relevée. Cet espace voué au tissage pourrait avoir été protégé par une simple toiture posée sur des poteaux, dont un second vestige a été mis au jour cette année $(163178, \text { fig. 20) })^{12}$. 
Fig. 20 - Pompéi, VI 16, 3-4, pièce 1. Sous la conduite d'eau moderne, trou de poteau (163178) permettant de maintenir la toiture disposée au-dessus de l'espace voué au tissage. Vue du nord.

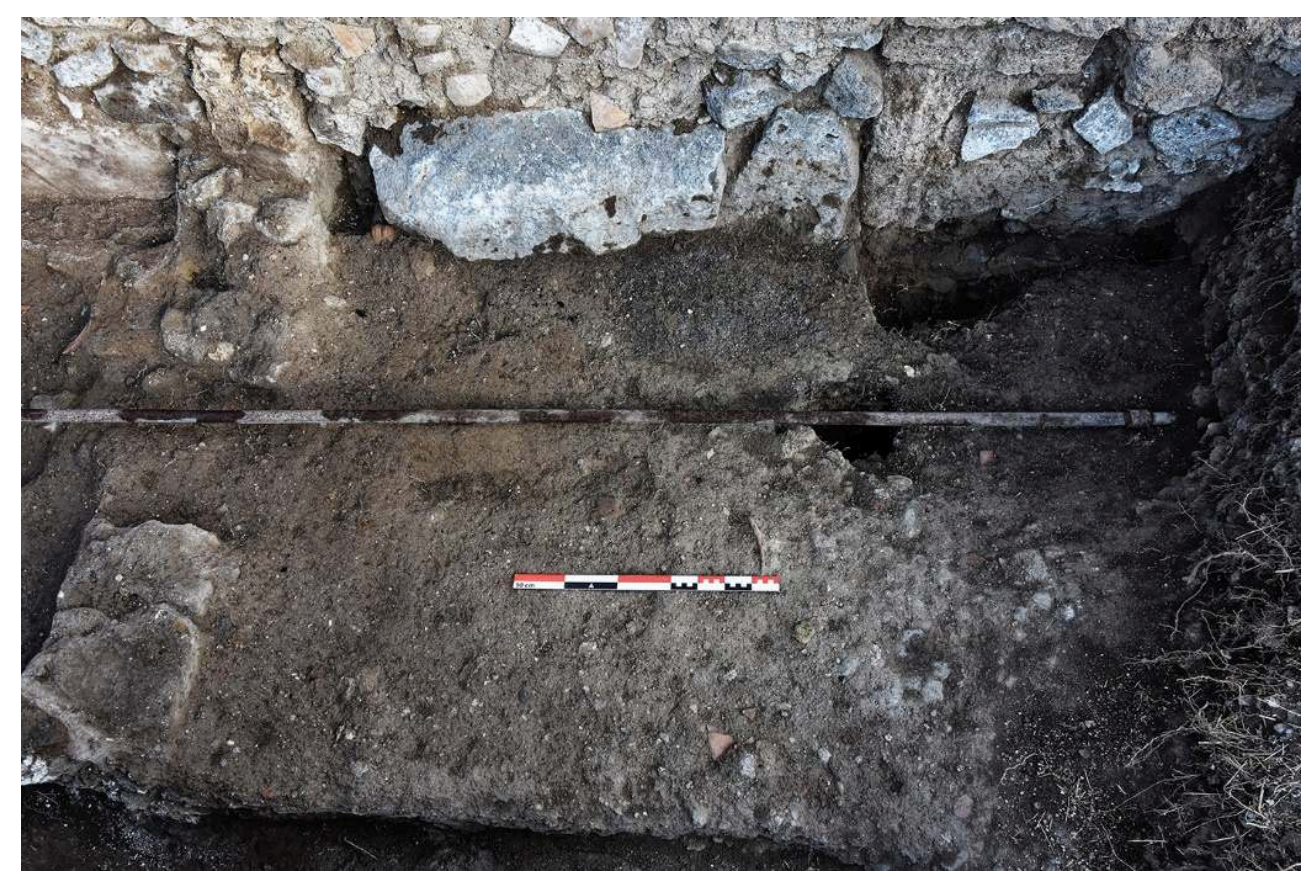

Cliché Mibac - PA Pompei / B. Ephrem / EFR. @ CC BY-NC-SA

Pour l'heure, nous considérons comme une hypothèse la mise en œuvre d'un premier bassin de rinçage (163227), lié à des activités de foulage à l'ultime fin de vie de l'atelier, au nord-ouest de la pièce 2 . En effet, l'étude des élévations montre clairement que ce bassin est antérieur à l'ensemble des autres constructions liées à la foulerie dans cette pièce. Par ailleurs, les différents niveaux d'enduits couvrant partiellement ce bassin soulignent qu'il a eu une vie plus longue que le bassin oriental: un premier niveau d'enduit court tout le long du bord méridional du bassin (163220), ensuite recouvert par l'enduit de dernière phase. La prochaine campagne cherchera à éprouver cette hypothèse, en tentant de voir si un premier système d'évacuation ne se trouvait pas dans la moitié occidentale de la pièce. Pour le reste, il est possible que des remaniements aient été effectués sur la citerne de la pièce 2, sans que l'avancée de la fouille permette d'avoir d'assurance sur ce point.

\section{Les derniers moments de l'atelier : modifications inachevées au moment de l'éruption}

$\mathrm{Au}$ moment de l'éruption, l'atelier ne pouvait plus fonctionner. En ce qui concerne la partie lavage de toisons et filage, la raison en est simple : le rattachement au réseau d'adduction en eau sous pression était doublement coupé. Le tuyau permettant de remplir l'ensemble des bassins, la chaudière, mais aussi les fontaines de la Casa degli Amorini Dorati, avait été coupé avant l'éruption, comme en témoigneraient les lapilli comblant le négatif d'arrachage d'une portion de la fistula (fig. 21-22). Au-delà de cette coupure très localisée, la mise en évidence d'une tranchée (163149) remplie de lapilli, zigzaguant depuis l'angle sud-oriental de l'atelier, permettra de rouvrir le débat sur l'approvisionnement en eau de Pompéi au moment de l'éruption ${ }^{13}$. En effet, au fond de celle-ci, et continuant vers l'est-sud-est, un tuyau en plomb de 0,08 $\mathrm{m}$ de largeur pour 
0,13 m de hauteur, soudure incluse ${ }^{14}$, a été observé sur une longueur de 1,35 m (fig. 15, 23). La tranchée était en cours de creusement au moment de l'éruption, avec un parcours allant du sud au nord ${ }^{15}$. Un tel diamètre ne se rencontre que peu dans l'hydraulique pompéienne ${ }^{16}$ : il est hautement probable qu'il s'agisse d'une conduite " principale », devant être connectée au château d'eau principal après sa mise en place le long de toute la façade orientale de l'îlot VI 16, ce qui cadrerait bien avec les autres tuyaux découverts en façade de la Casa degli Amorini Dorati, probablement en phase de récupération selon l'hypothèse d'A. Maiuri ${ }^{17}$.

Fig. 21 - Pompéi, VI 16, 3-4, pièce 1. Entre les deux triangles, court le tuyau en plomb 163010 et son arrachage, rempli de lapilli. À l'est, la banquette d'installation des métiers à tisser verticaux (163037), à l'ouest la fosse moderne pour gâcher de la chaux. Vue de l'est.

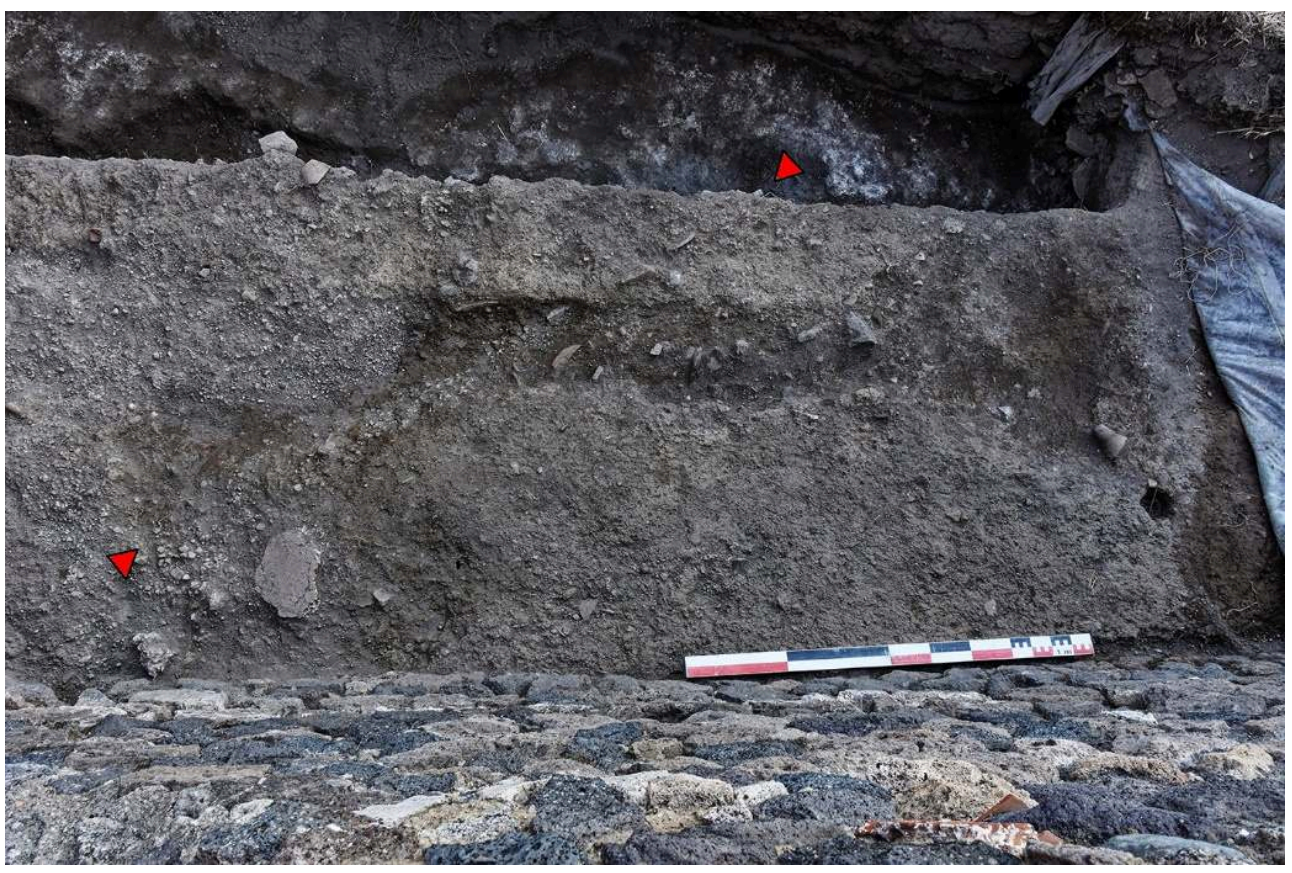

Cliché Mibac - PA Pompei / N. Monteix / EFR. @ CC BY-NC-SA. 
Fig. 22 - Pompéi, VI 16, 3-4, pièce 1. Le tuyau en plomb 163010 et son arrachage en cours de fouille. À l'est, la banquette d'installation des métiers à tisser verticaux (163037). Vue de l'ouest.

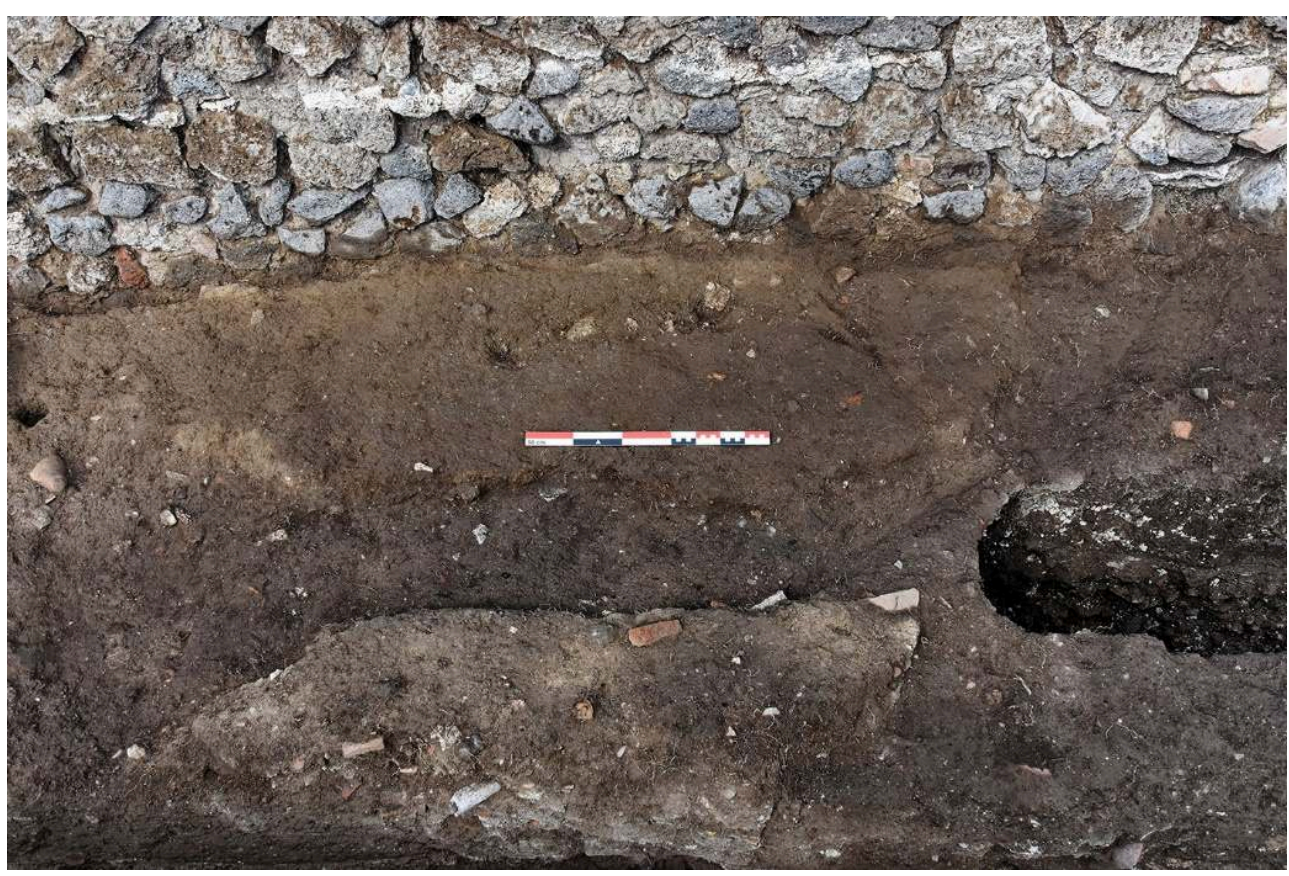

Cliché Mibac - PA Pompei / B. Ephrem / EFR. @ CC BY-NC-SA.

Fig. 23 - Pompéi, VI 16, 3-4, pièce 1. Coupe sur les lapilli remplissant la tranchée (163149) de pose d'une canalisation d'adduction d'eau en plomb. Vue du nord.

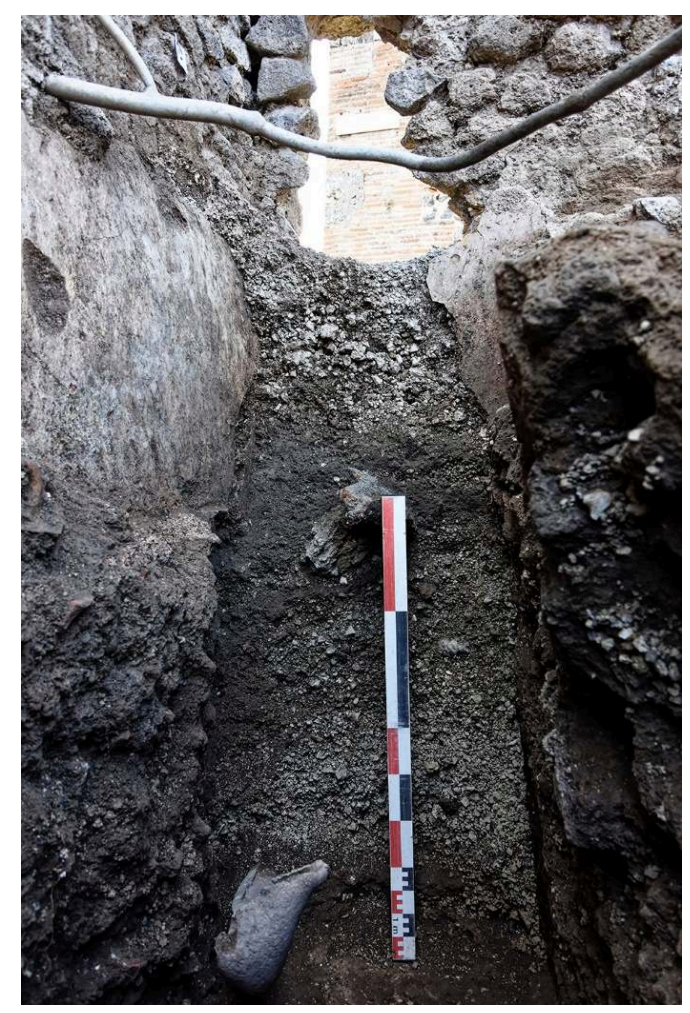

Cliché Mibac - PA Pompei / B. Ephrem / EFR. @ CC BY-NC-SA 
Dans le reste de l'atelier, ce qui marque cette ultime phase est la mise en place, restée inachevée, d'une foulerie comportant deux bassins de rinçage et trois stalles de foulage (fig. 24-25). Les deux bassins sont disposés sur une sorte de podium, haut d'environ $0,25 \mathrm{~m}$, constitué de remblai, limité au sud par un alignement de blocs de basalte (163210) et majoritairement de calcaire du Sarno (163211). Dans sa partie occidentale, limitée à l'est par la canalisation d'évacuation des bassins, le remblai du podium est recouvert d'un niveau de béton de tuileau (163218) au centre duquel des tuiles ont été alignées sur toute la longueur (163213). Au nord de celles-ci, un « escalier» (163221) a été ménagé avec des blocs de remploi, dont un en travertin, probablement issu d'un complexe monumental non déterminé. Un enduit de tuileau (163219) recouvre le bassin et l'escalier. À l'est de ce dernier, un bassin de drainage (163222) permettait la vidange des deux bassins ${ }^{18}$, en se vidant lui-même dans une canalisation (163215) dont seule la première portion est protégée sur 1,65 m par des tuiles couvre-joints en remploi ; elle poursuit ensuite, après avoir fait un coude à 90 degrés, dans un simple creusement à peine marqué par un "radier» de pierres (163216; fig. 26). À l'est de cette canalisation, le podium continue, en correspondance partielle avec la largeur du second bassin (163252) sans avoir toutefois bénéficié d'un quelconque revêtement de surface : le remblai semblait, lors de la fouille, avoir été à peine posé, et peu compacté. En dehors de l'emprise du podium, en particulier au sud et à l'est, le sol n'était guère plus aménagé. Des fosses ont été comblées peu avant l'éruption, le comblement de celle au sud (163202) étant resté inachevé, comme en témoigne le dépôt de cendre volcanique observé à sa surface. À l'est du second bassin, une accumulation de moellons et de sédiment a été observée (163228). L'irrégularité de sa forme en plan et de sa surface laisse supposer là encore un dépôt précédant de peu l'éruption. Au nord de cette accumulation, trois murets (163247-163249) ont été érigés contre le mur de refend de la pièce 3, constituant autant de stalles. Cependant, à la suite de M. Flohr ${ }^{19}$, nous avons constaté l'absence de tout récipient de quelque nature que ce soit à la base de ces stalles, alors même que des traces labiles d'enduit hydraulique ont été observées sur les parois des murets. 
Fig. 24 - Pompéi, VI 16, 3-4. Plan de l'ultime phase de l'atelier, peu avant l'éruption.

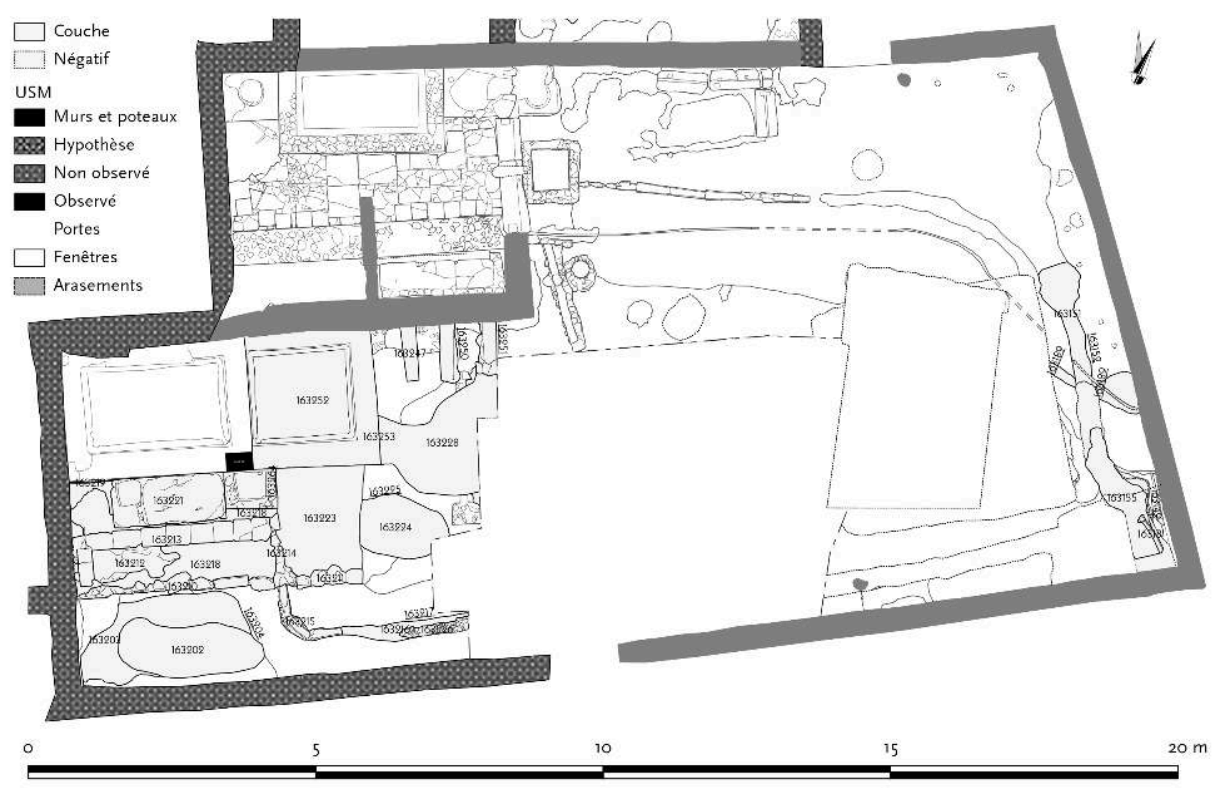

Relevé, dessin : F. Fouriaux / N. Monteix / EFR. @ CC BY-NC-SA.

Fig. 25 - Pompéi, VI 16, 3-4. Orthophotogrammétrie de la foulerie (pièce 2) lors de l'ultime phase de l'atelier, peu avant l'éruption.

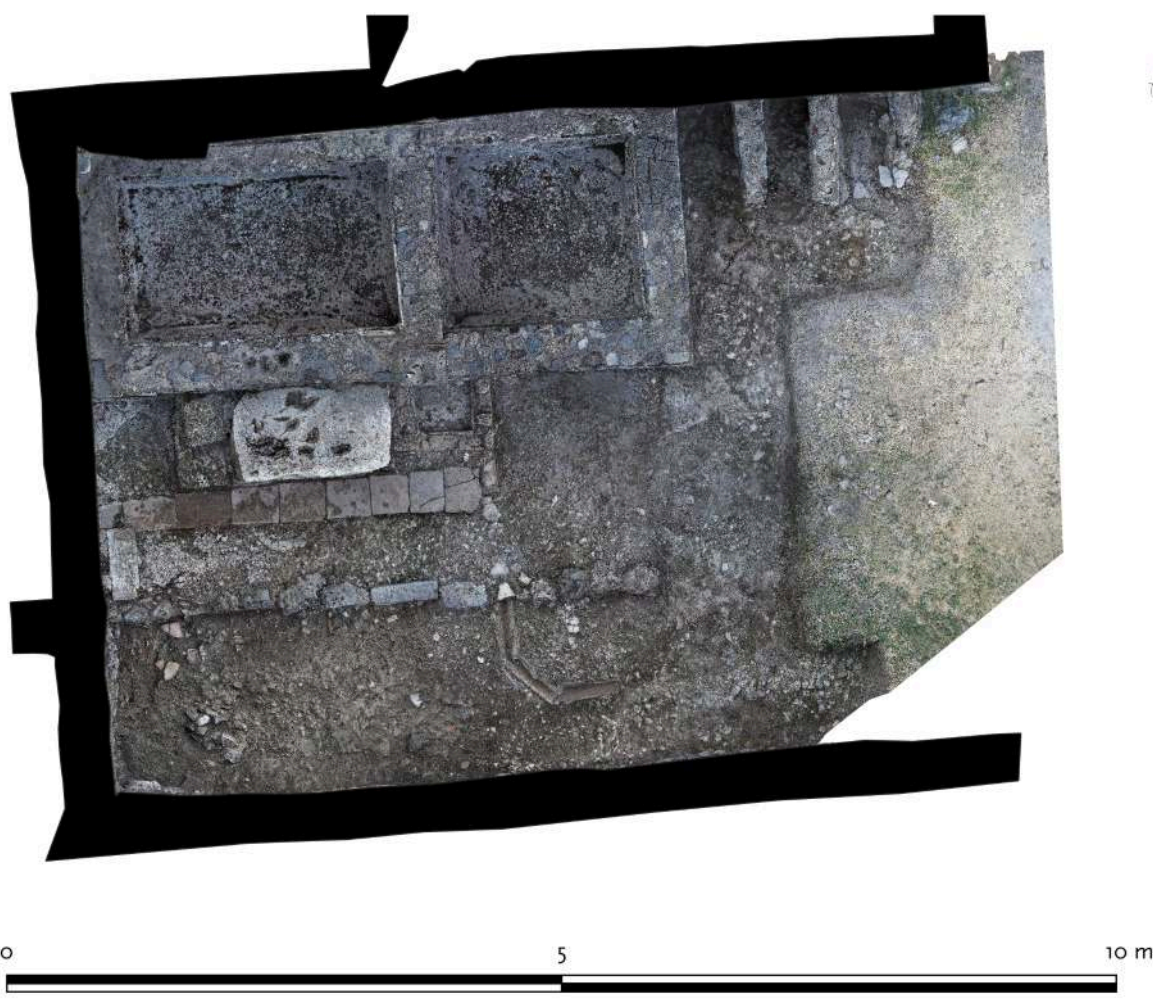

Relevé : F. Fouriaux / N. Monteix / EFR. @ C CC BY-NC-SA. 
Fig. 26 - Pompéi, VI 16, 3-4. Canalisation de vidange des deux bassins de rinçage. Prise depuis le podium (163223, au nord).

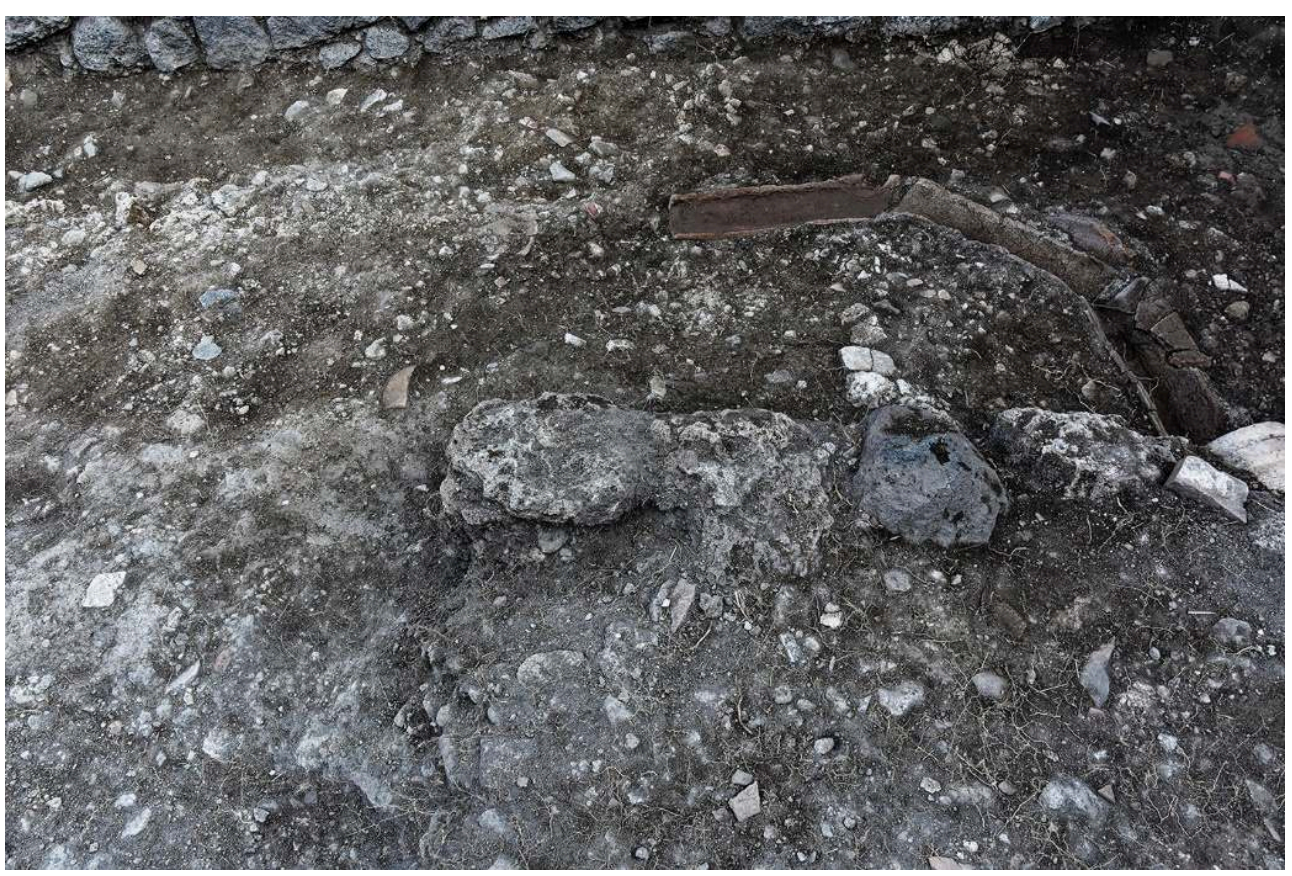

Cliché Mibac - PA Pompei / F. Fouriaux / EFR. @ C CC BY-NC-SA.

Comme nous le signalions plus haut, l'analyse du bâti et des relations entre ces différents éléments montre que le premier bassin a eu une vie propre avant que ne lui soient adjoints l'ensemble des autres éléments (second bassin, système de drainage, moitié occidentale du podium, escalier, moitié orientale du podium). L'incomplétude du podium, l'état des différents remblais observés et l'absence de récipient au fond des stalles apparaissent sans appel: cette foulerie n'était qu'en voie d'achèvement au moment de l'éruption; elle avait probablement été précédée par une autre implantation, utilisant le premier bassin de rinçage, dont les restes sont encore à découvrir.

\section{La boutique VI 16, 5}

Une exploration stratigraphique de la boutique située en VI 16,5 a également été menée au cours de cette campagne (fig.1). L'idée de départ était de vérifier les remarques peu claires proposées par A. Sogliano lors de la publication initiale de cet espace $^{20}$, tout en s'offrant la possibilité d'insérer les deux ateliers liés à la production textile (VI 16,3-4 et VI 16,6) dans un contexte élargi et ramifié jusqu'à la Casa degli Amorini Dorati en avant de laquelle ces espaces se développent ${ }^{21}$. Cette année, seule la moitié méridionale de la pièce 1 a été fouillée, en raison notamment de la présence de perturbations modernes: une canalisation antique a été réutilisée pour évacuer les eaux pluviales du péristyle de la Casa degli Amorini Dorati, puis une seconde canalisation, venant de VI 16,6, s'y est adjointe, occasionnant une rupture complète des relations stratigraphiques entre le nord et le sud de la pièce (fig. 27). 
Fig. 27 - Pompéi, VI 16, 5. Perturbations modernes dans la boutique VI 16, 5.
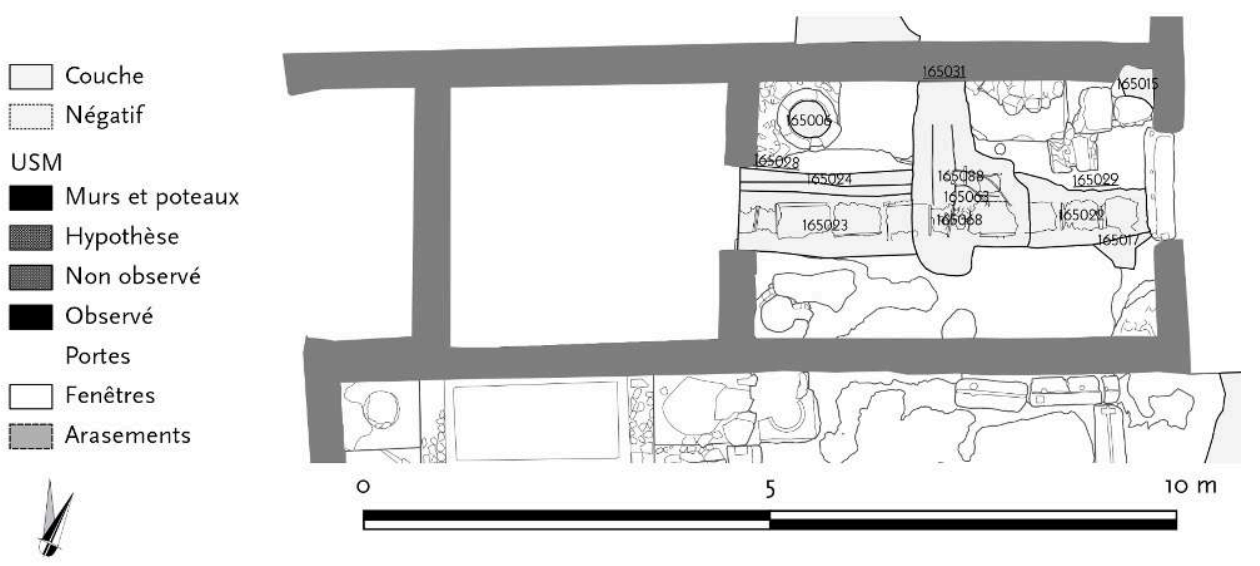

Relevé, dessin : F. Fouriaux / N. Monteix / EFR. (C) CC BY-NC-SA.

\section{Première occupation observée : fin du $\|^{\mathrm{e}} \mathrm{s}$. av. n.è.}

Alors même que la fouille a atteint la profondeur maximale de 35,00 m s.l.m., les niveaux éruptifs anté-pliniens n'ont pas été observés dans cet espace ${ }^{22}$. La première occupation observée renvoie à un mur sur le côté méridional de la pièce (fig. 28). Il est hautement probable que ce mur s'ouvrait vers VI 16,34 dont la situation est inconnue à cette période. La maçonnerie est constituée de moellons de basalte. En correspondance altimétrique du niveau de sol observé pour cette phase (165075), et en correspondance topologique avec les piédroits d'un passage postérieur, des blocs se substituent aux moellons ; entre eux, on observe une maçonnerie (165080) pouvant correspondre à un bouchage de porte, également postérieur. Le niveau de remblai (165082) s'appuyant sur ce mur n'a pas été fouillé ; il servait de fondement à un épais niveau (165075, ca. 0,30 m) dont la surface présentait les stigmates caractéristiques des sols. Le matériel contenu dans ce sol, dont plusieurs fragments de plats à vernis rouge pompéien, permet de

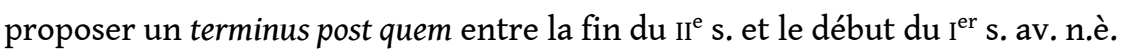

Fig. 28 - Pompéi, VI 16, 5. Plan de la phase de la fin du ॥e s. av. n.è.
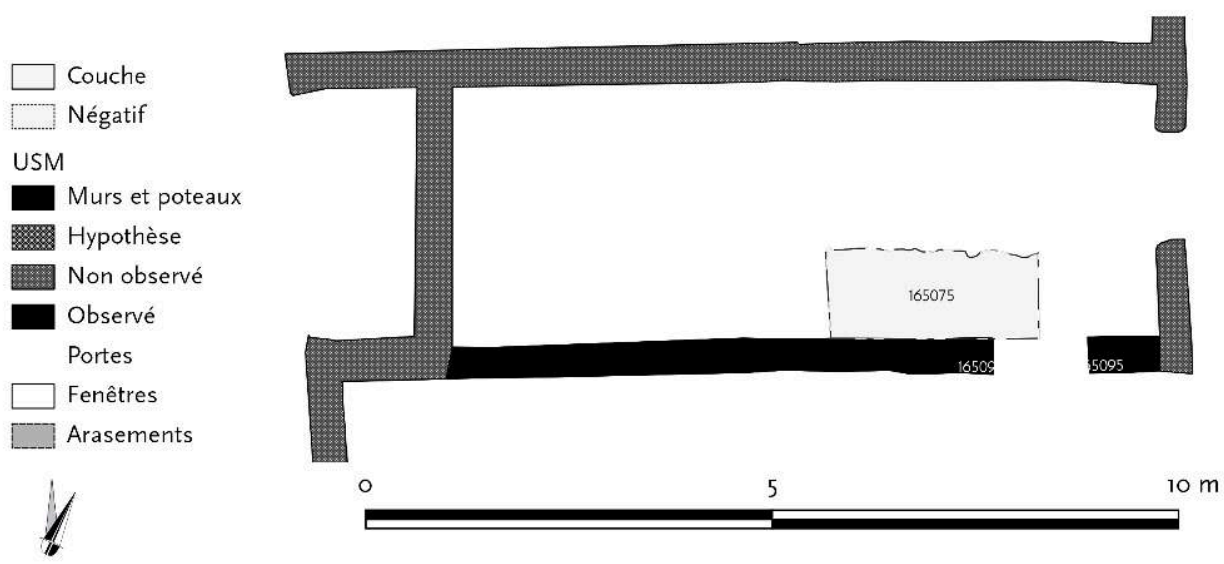

Relevé, dessin : F. Fouriaux / N. Monteix / EFR. @ CC BY-NC-SA. 


\section{Au $\mathrm{I}^{\text {er }} \mathbf{S}$. av. $\mathrm{n}$. è. : réaménagements en lien avec la construction de la Casa degli Amorini Dorati}

Dans le courant du $\mathrm{I}^{\mathrm{er}} \mathrm{s}$. av. n. è., les changements visibles dans cet espace trahissent la mise en œuvre de travaux largement plus conséquents, en ce qu'ils touchent à la réalisation de la Casa degli Amorini Dorati (fig. 29). La première des transformations survenues a consisté à boucher la porte permettant d'accéder à l'espace [VI 16, 3-4] (165080 ; fig. 30). Ce bouchage apparaît comme la seule opération touchant au gros œuvre : immédiatement après, les murs sont enduits (163052). À la base de ceux-ci, le trop-plein de mortier est jeté en vrac, ce qui permet accessoirement d'assurer une bonne continuité de l'enduit de la base du mur à son sommet (fig. 31).

Fig. 29 - Pompéi, VI 16, 5. Plan de la phase du fer s. av. n.è.
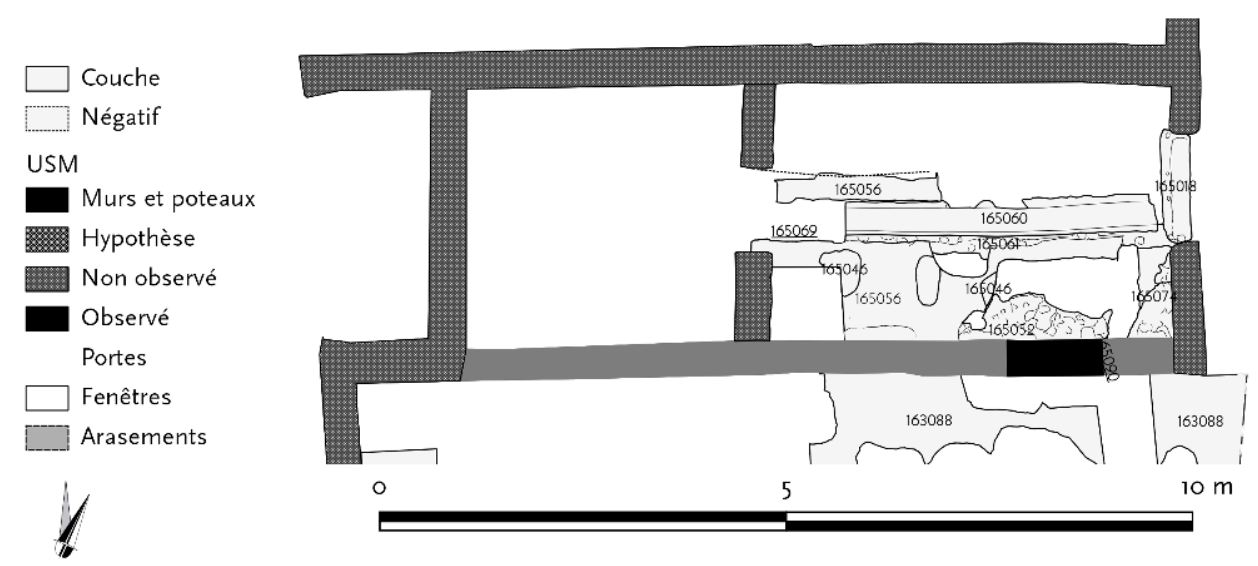

Relevé, dessin : F. Fouriaux / N. Monteix / EFR. @ C CC BY-NC-SA. 
Fig. 30 - Pompéi, VI 16, 5. Stratigraphie du bâti au niveau de la porte méridionale. Les US indiquées en italique correspondent aux niveaux de sol observés dans la pièce.

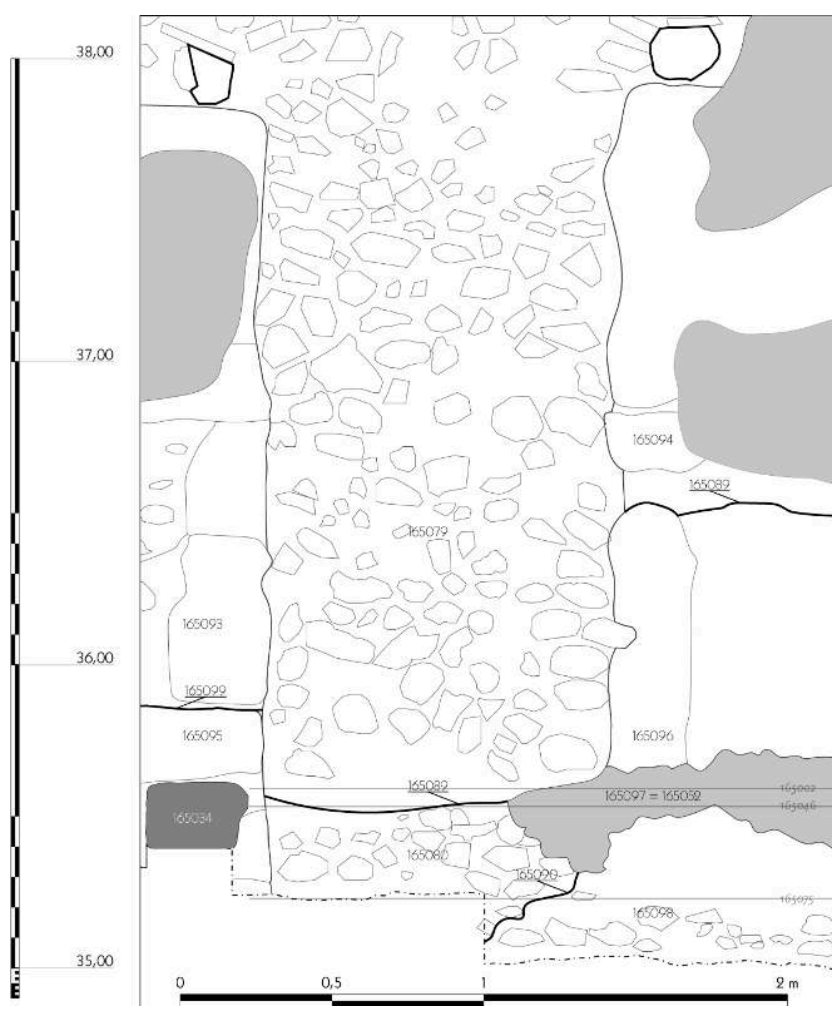

Relevé / dessin : N. Monteix / J. Devogelaere / EFR. @ CC BY-NC-SA. 
Fig. 31 - Pompéi, VI 16, 5. Niveau d'enduit (165052) laissé au pied de la paroi après son application sur le mur. Vue du nord.

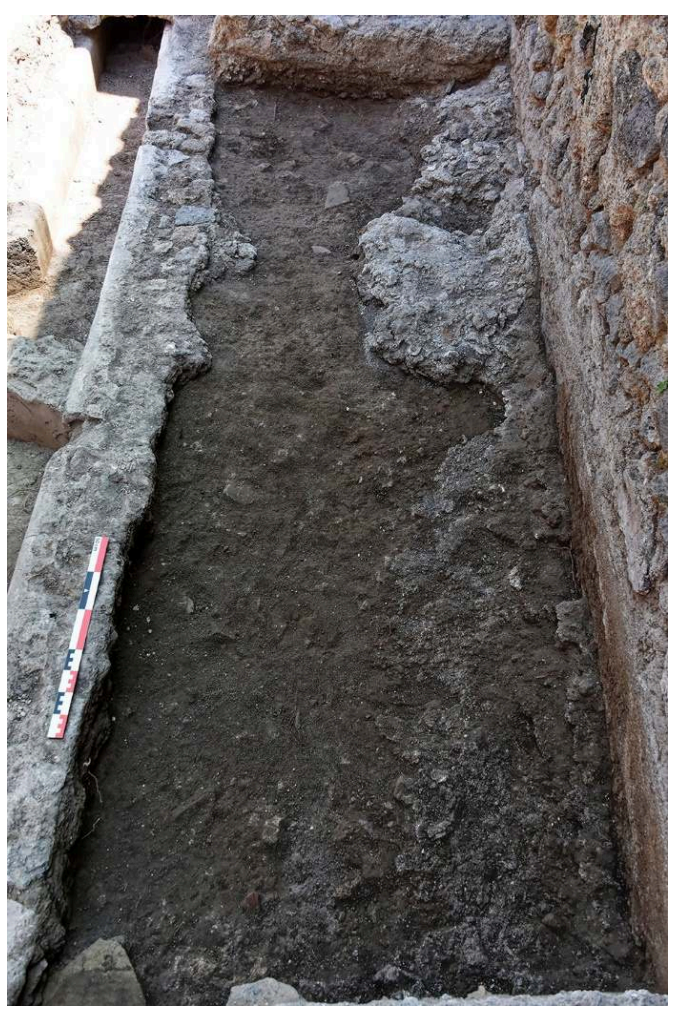

Cliché Mibac - PA Pompei / J. Devogelaere / EFR. @ C CC BY-NC-SA.

Après le dépôt d'une fine couche de sable basaltique, probable résidu de la préparation des enduits, une canalisation a été construite sur toute la longueur de la pièce - et en fait, selon toute vraisemblance, sur toute la longueur de la boutique - pour servir d'exutoire au trop-plein des citernes récupérant les eaux pluviales du péristyle de la Casa degli Amorini Dorati. Coulée dans une tranchée fermée, seul son conduit, profond et large de $0,32 \mathrm{~m}$, est très soigneusement réalisée ${ }^{23}$. Par la suite, deux niveaux de remblai (163057 et 165056$)^{24}$ ont été déposés afin de procéder à un exhaussement total du niveau de circulation de 0,30 à $0,40 \mathrm{~m}$, permettant au passage une régularisation de la surface (fig. 32-33). À la fin des travaux, un niveau de terre battue s'est progressivement formé (165046). C'est également au cours de cette phase que cet espace est doté d'un seuil à rainures, caractéristique des espaces commerciaux ou de production.

Bien que l'étude du matériel soit loin d'être achevée, plusieurs éléments doivent être signalés. Tout d'abord, en termes de datation, aussi bien des restes d'assiettes en campanienne $A$ et $B$ qu'une partie de la céramique culinaire donnent un faciès ayant plutôt un terminus post quem au $\mathrm{I}^{\mathrm{er}} \mathrm{s}$. av. n.è., voire vers le milieu de ce siècle. Cette datation, qui demandera à être encore précisée, valide les propositions de datations formulées sur critères stylistiques par F. Seiler lors de son étude de la Casa degli Amorini Dorati ${ }^{25}$. Un second point mérite d'être noté : les différents niveaux de remblais se sont montrés particulièrement riches en résidus du travail du fer. Si les nombreuses scories mises au jour pourraient n'être que matière à grossir un remblai fait de tout venant, il est moins intéressant de sélectionner des battitures pour le même usage. Dès lors, il 
nous faut considérer que, pour la mise en place de cet exhaussement, les niveaux de sol d'un atelier de métallurgie du fer ont été excavés et transportés ${ }^{26}$ en VI 16, 5.

Fig. 32 - Pompéi, VI 16, 5. Vue des différents remblais mis en place au fer $\mathbf{s}$. av. $n$. è. lors de la création de la canalisation issue de la Casa degli Amorini Dorati.

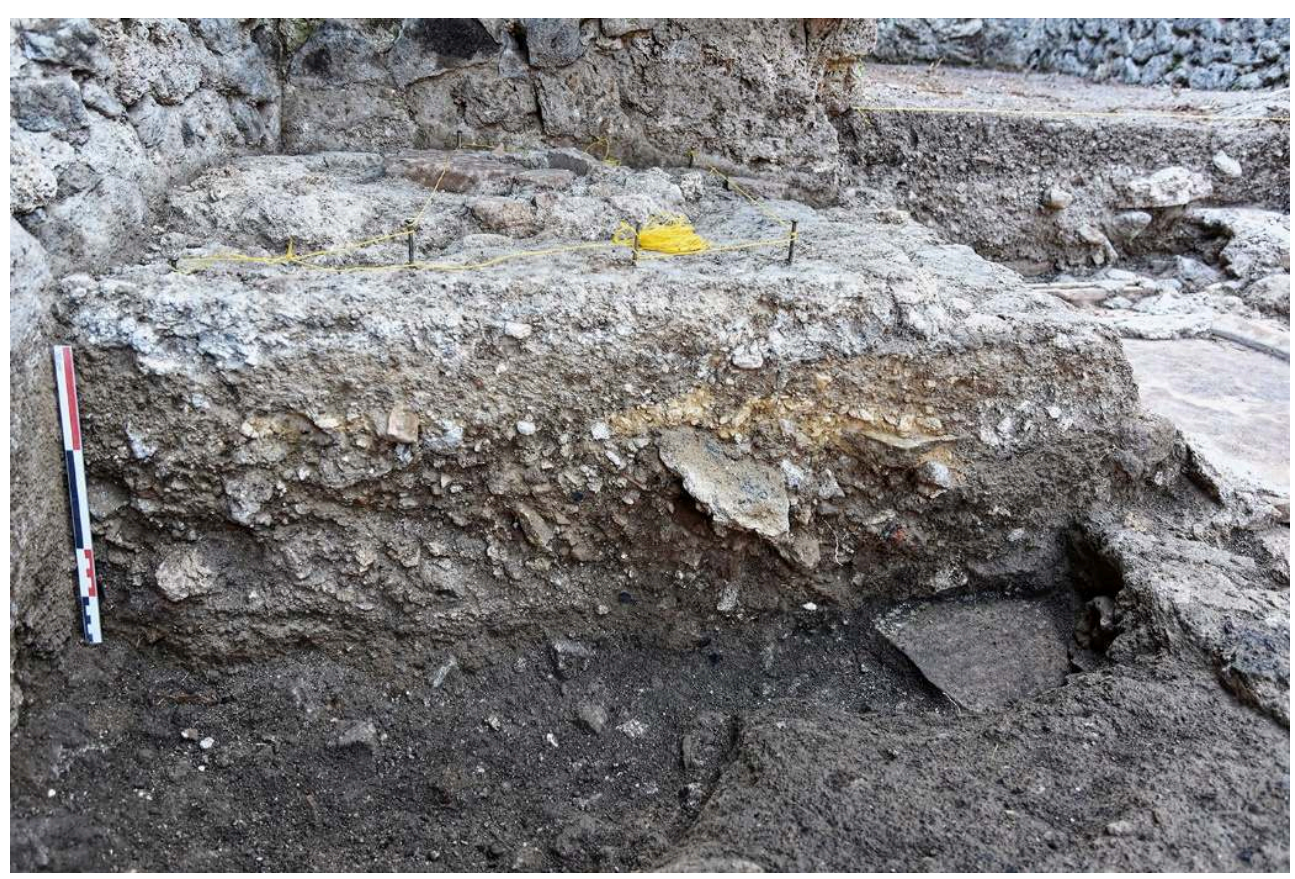

Cliché Mibac - PA Pompei / J. Devogelaere / EFR. @ C CC BY-NC-SA.

Fig. 33 - Pompéi, VI 16, 5. Coupe sud-nord dans la partie occidentale de la pièce 1.

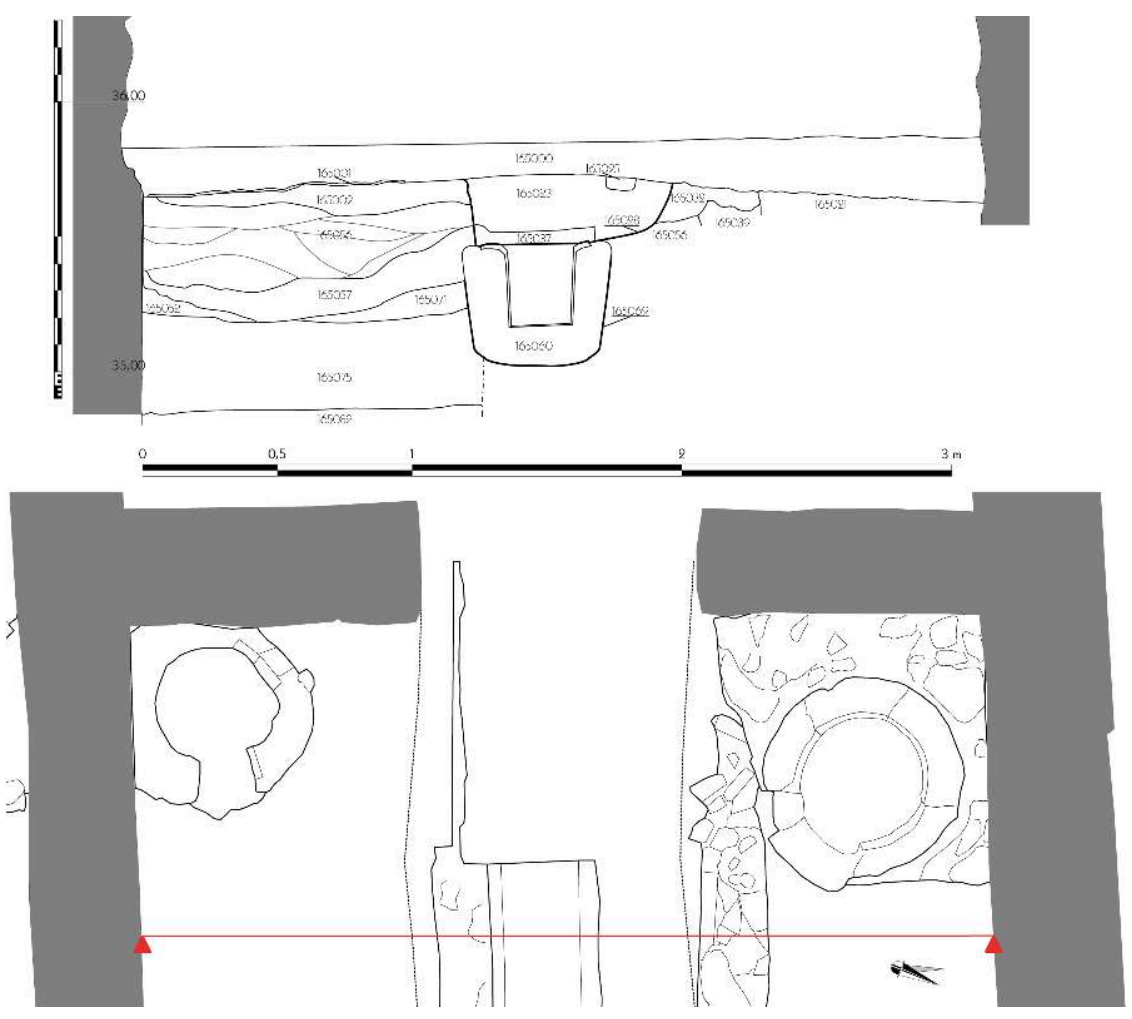

Relevé / dessin : N. Monteix / F. Fouriaux / EFR. (C) CC BY-NC-SA. 


\section{Première moitié du er $^{\text {s }}$. de n.è. : transformation des liens avec le voisinage et aménagements hydrauliques}

31 La phase suivante, placée dans la première moitié du $\mathrm{I}^{\mathrm{er}} \mathrm{s}$. de n.è., voit deux transformations, probablement concourantes quoique non liées, être mises en place (fig. 34). D'une part, la communication avec l'espace [VI 16, 3-4] est recréée. Après le creusement d'une fosse quadrangulaire (165054), profonde de 0,20 à $0,30 \mathrm{~m}$, large de $1 \mathrm{~m}$ et longue d'au moins $1,60 \mathrm{~m}$, en correspondance de la porte ouverte précédemment, le passage vers le sud est rouvert (fig. 35-36). Dans un second temps, un muret (165034), également en correspondance du montant oriental de la porte, nonobstant son plan légèrement courbé, est érigé27.

Fig. 34 - Pompéi, VI 16, 5. Plan de la phase du Ier s. de n.è.
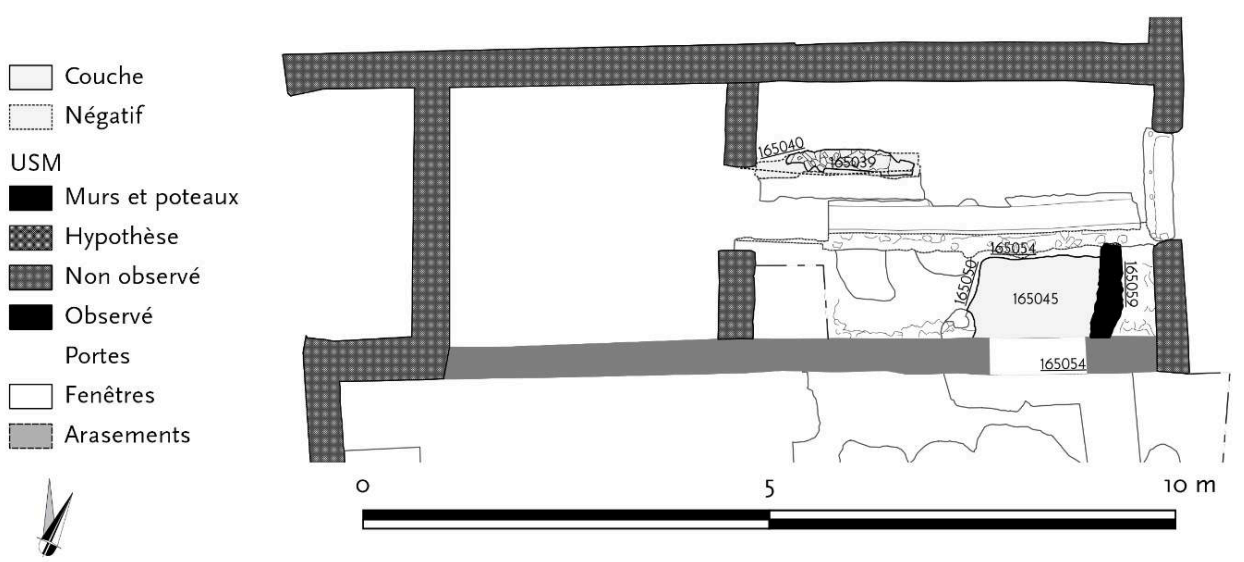

Relevé, dessin : F. Fouriaux / N. Monteix / EFR. (C CC BY-NC-SA. 
Fig. 35 - Pompéi, VI 16, 5. Fosse liée à la réouverture de la porte vers VI 16, 3-4. Vue du nord.

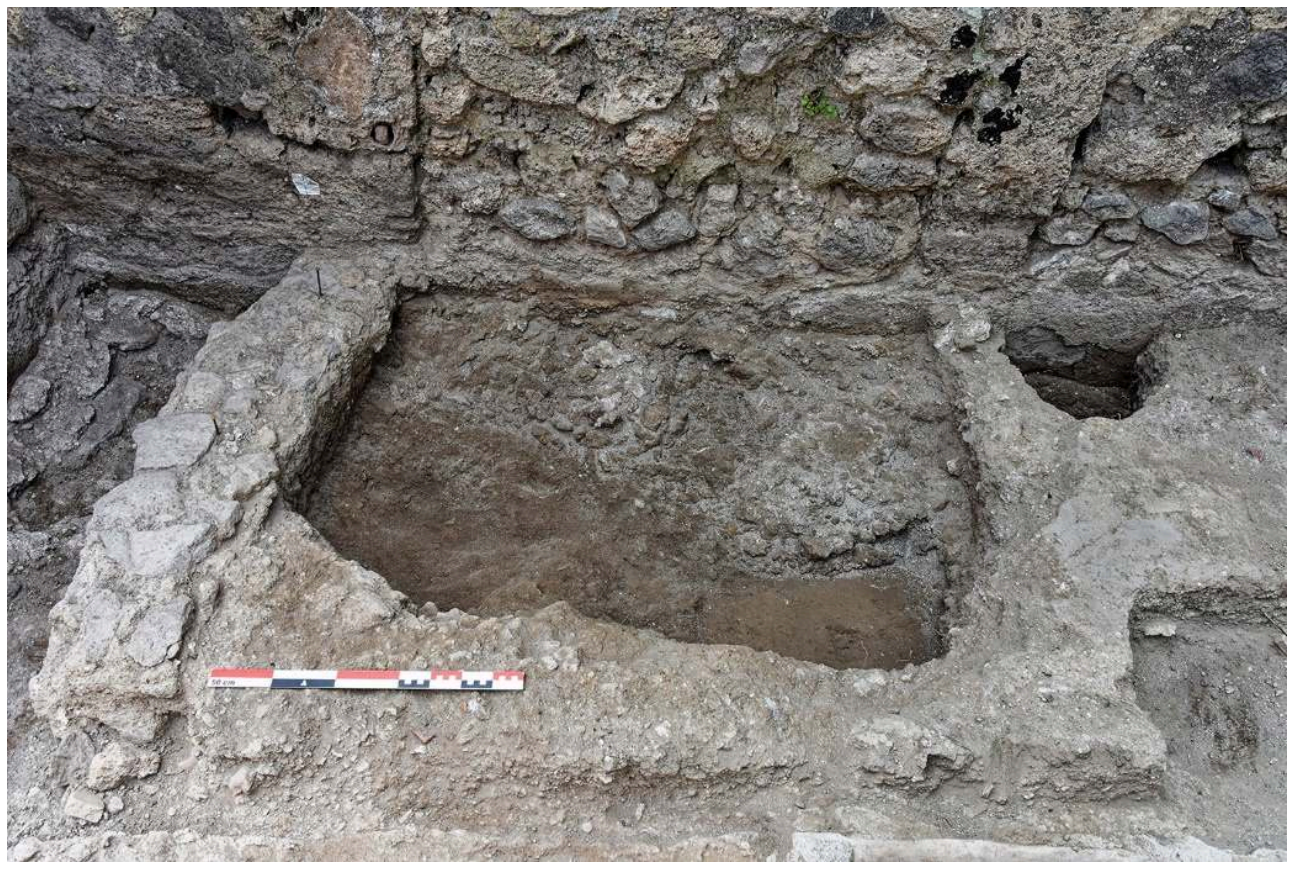

Cliché Mibac - PA Pompei / J. Devogelaere / EFR. @ C CC BY-NC-SA.

Fig. 36 - Pompéi, VI 16, 5. Coupe est-ouest en avant de la porte méridionale.
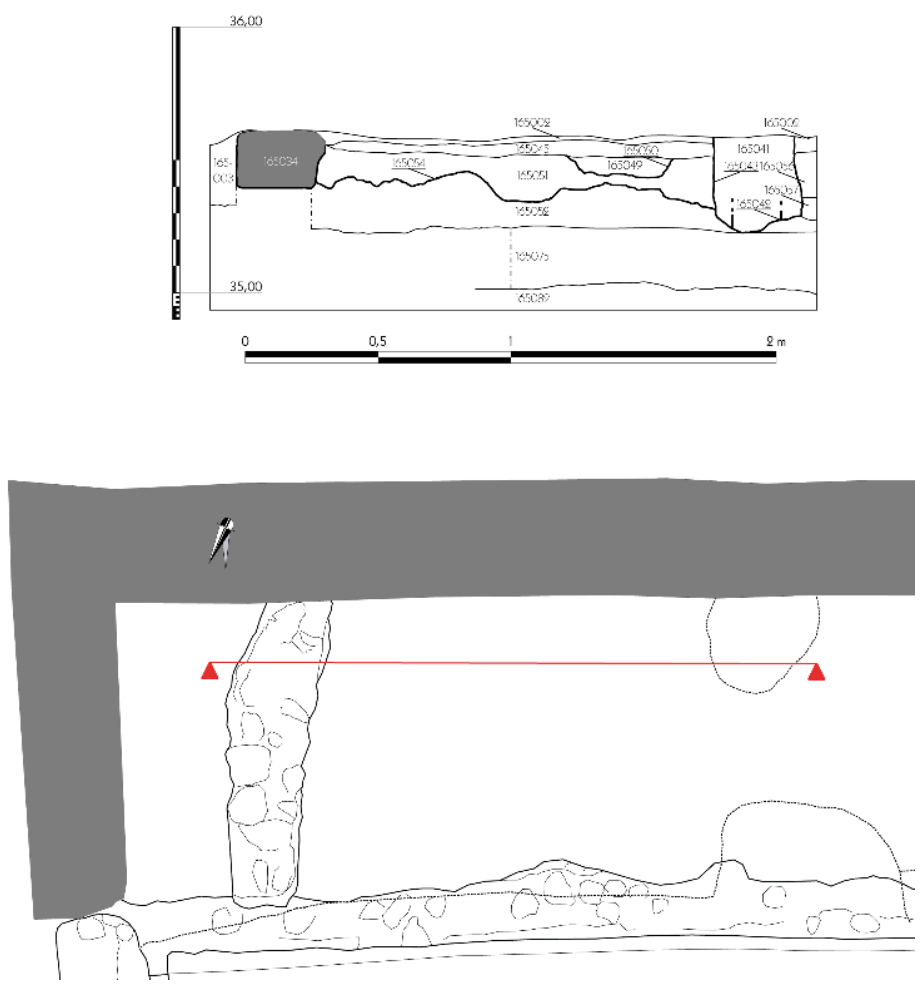

Relevé / dessin : N. Monteix / F. Fouriaux / EFR. @ CC BY-NC-SA.

De l'autre côté de la pièce, parallèlement à la canalisation du trop-plein du péristyle de la Casa degli Amorini Dorati et au nord de celle-là, la couverture en tuiles d'une seconde canalisation, de taille beaucoup plus réduite, a été mise au jour (165039, fig. 37). 
Servant d'appui à la bouche de citerne qui fut installée plus tard, elle ne saurait lui être liée. Il est probable que l'extension de la fouille dans la pièce 2 lors d'une prochaine campagne permettra de mieux apprécier cet aménagement hydraulique.

Fig. 37 - Pompéi, VI 16, 5. Vue des différents aménagements hydrauliques mis au jour en VI 16, 5. De gauche à droite, la bouche de citerne 165004, la canalisation 165039, et la couverture moderne de la canalisation provenant de la Casa degli Amorini Dorati. Vue de l'ouest.

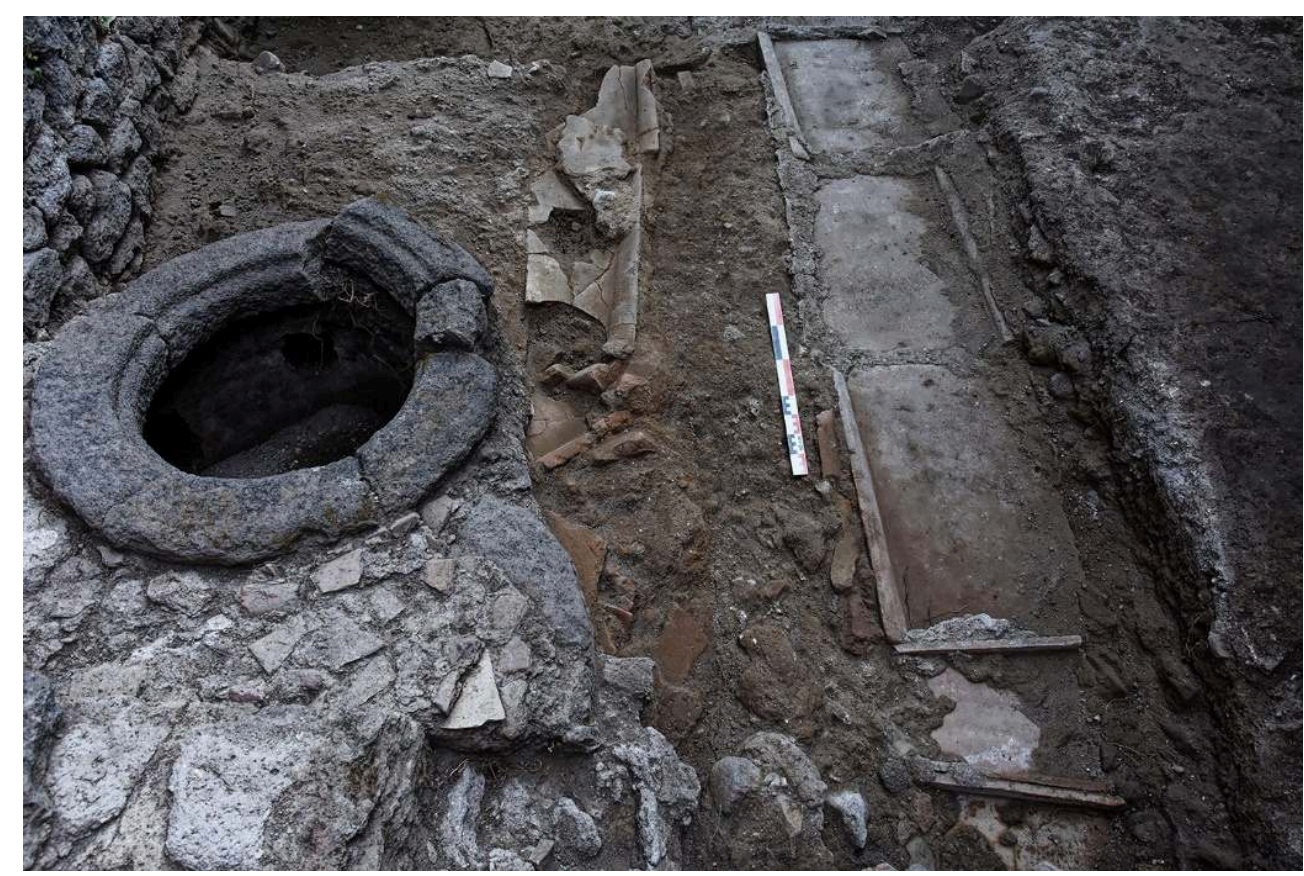

Cliché Mibac - PA Pompei / J. Devogelaere / EFR. @ C CC BY-NC-SA.

\section{Du séisme de 62/63 à l'éruption : une boutique indépendante avec espace d'habitation}

Les dégâts causés par le séisme de 62/63 paraissent avoir été réparés en reproduisant le plan initial. Pour l'heure, dans l'attente d'une étude approfondie des élévations dans la pièce 2 , nous signalerons juste la réfection intégrale du mur méridional, porte et montants inclus, comme dommages restaurés (fig. 38, en haut). Dans un second temps, l'espace est transformé de façon assez radicale. D'une part, la communication avec VI 16, 3bis-4 est rompue, à la suite du bouchage de la porte (165079).

Parallèlement, et sans que le lien ne soit complètement évident en l'absence de toute connaissance sur le plan de VI 16, 3bis-4 avant le séisme, deux aménagements tendent à transformer cette boutique en espace mixte, où le boutiquier jouirait d'un appartement à l'étage au-dessus de son commerce (fig. 38, en bas). Tout d'abord, une bouche de citerne (165004) est implantée dans l'angle nord-occidental de la pièce. Elle s'appuie sur un massif maçonné (165005) et a contribué à la destruction de la petite canalisation (165039). Surtout, un dé d'escalier, constitué d'un bloc de calcaire du Sarno, est installé le long du mur septentrional (165011, fig. 39). Il pourrait avoir fonctionné avec le poteau (165042), appuyé contre le mur méridional, qui aurait permis la mise en place d'une trémie pour accéder à l'étage. 
Fig. 38 - Pompéi, VI 16, 5. Plan des dégâts causés par le séisme de 62/63 (en haut) et des transformations successives à celui-ci (en bas).

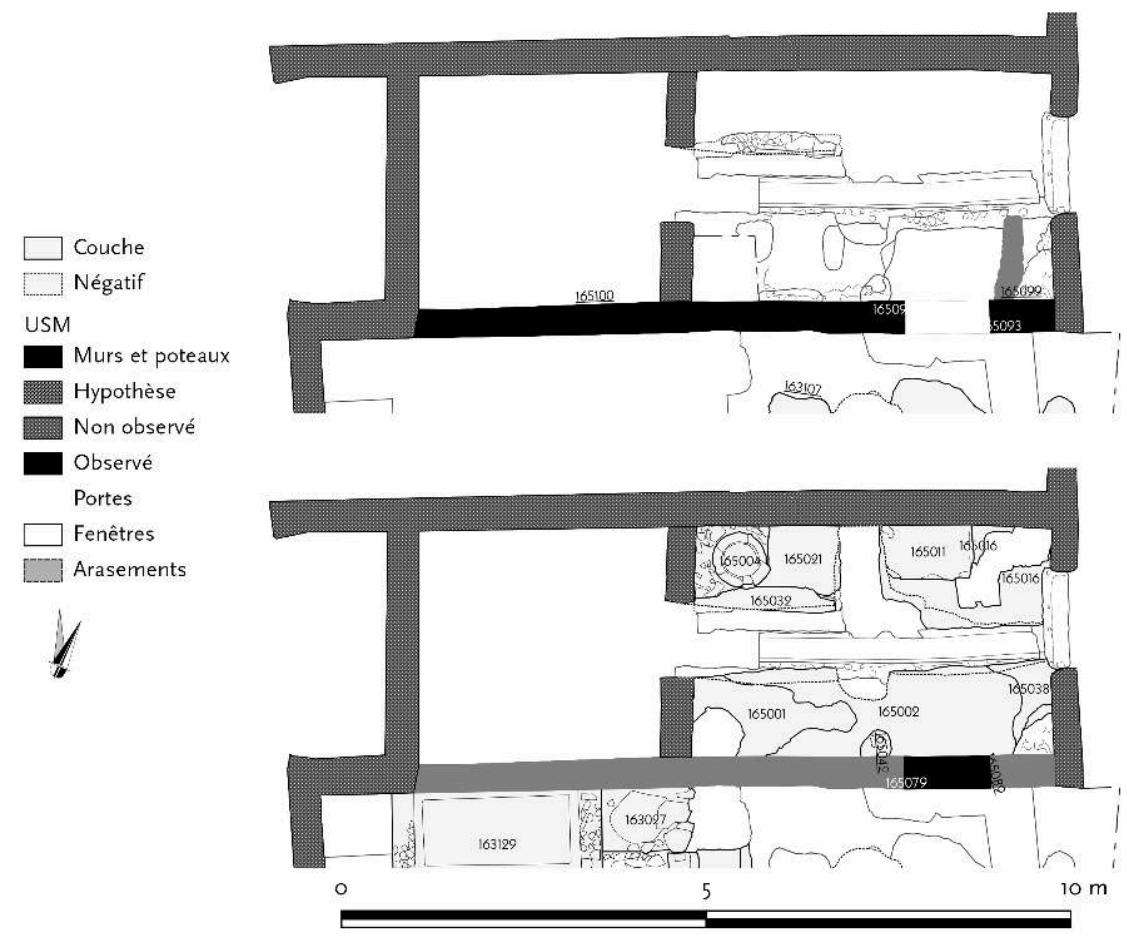

Relevé, dessin : F. Fouriaux / N. Monteix / EFR. @ C CC BY-NC-SA.

Fig. 39 - Pompéi, VI 16, 5. Escalier (165011) et éléments ajoutés dans une phase postérieure. Vue du sud.

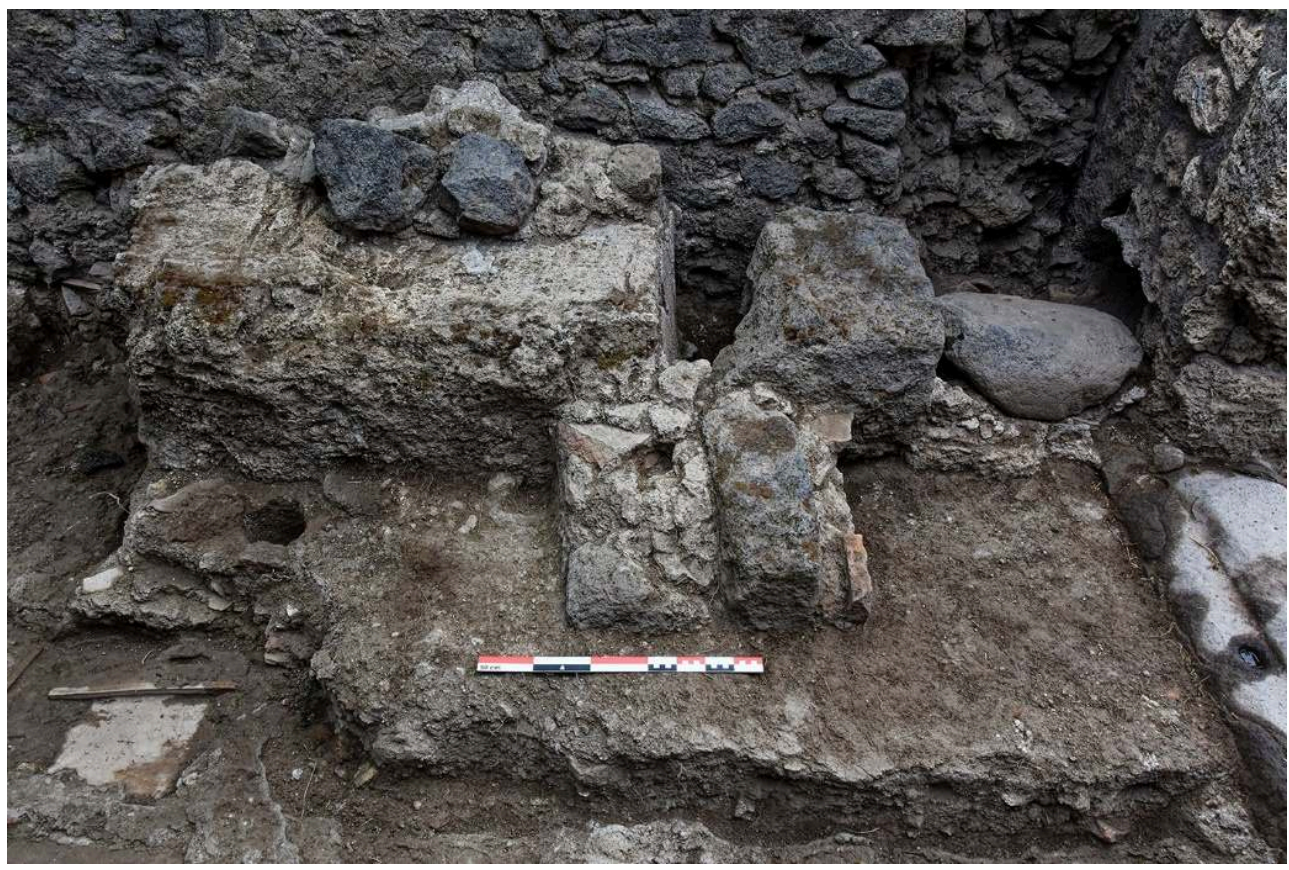

Cliché Mibac - PA Pompei / J. Devogelaere / EFR. @ C CC BY-NC-SA. 
Aucun dégât pouvant être lié à un éventuel second séisme n'a été mis en évidence. Cependant, la dernière phase montre des transformations non nulles (fig. 40). D'une part, l'escalier subit des variations : il gagne deux marches, l'une à l'est et l'autre au sud, étonnamment placées dans la proximité immédiate du fusorium d'A. Sogliano, en fait, une latrine (165076) qui s'évacue vers la façade, probablement dans une fosse septique installée sur le trottoir. En lien probable avec ce nouvel aménagement des marches, le poteau précédemment installé est remblayé (165041), remplacé par un autre (165036), plus proche du départ d'escalier. Il faudrait éventuellement voir ces transformations comme un changement d'escalier, qui serait passé de marches pleines à échelle de meunier. Enfin, seule trace possible d'une activité commerciale, un clibanus, four à pain à sole verticale, est installé dans l'angle sud-ouest de la pièce (fig. 41). Contrairement à l'autre exemple connu à Pompéi, découvert dans la boulangerie VII $12,7^{28}$, il s'agit d'une simple construction maçonnée, non renforcée par le remploi d'un dolium. Sa gueule s'ouvre vers l'est. Il est par ailleurs légèrement plus petit : son emprise est un cercle de 0,67-0,68 $\mathrm{m}$ de diamètre, tandis qu'il dispose d'une chambre de chauffe d'un diamètre de $0,43 \mathrm{~m}$. Si un tel aménagement peut renvoyer à une activité de production à visée commerciale, on ne peut exclure, en raison de sa petite taille, qu'il relève simplement d'une activité domestique: il serait prudent d'attendre le nettoyage des derniers niveaux de la pièce 2 avant de conclure.

Fig. 40 - Pompéi, VI 16, 5. Plan des dernières transformations survenues dans la boutique.
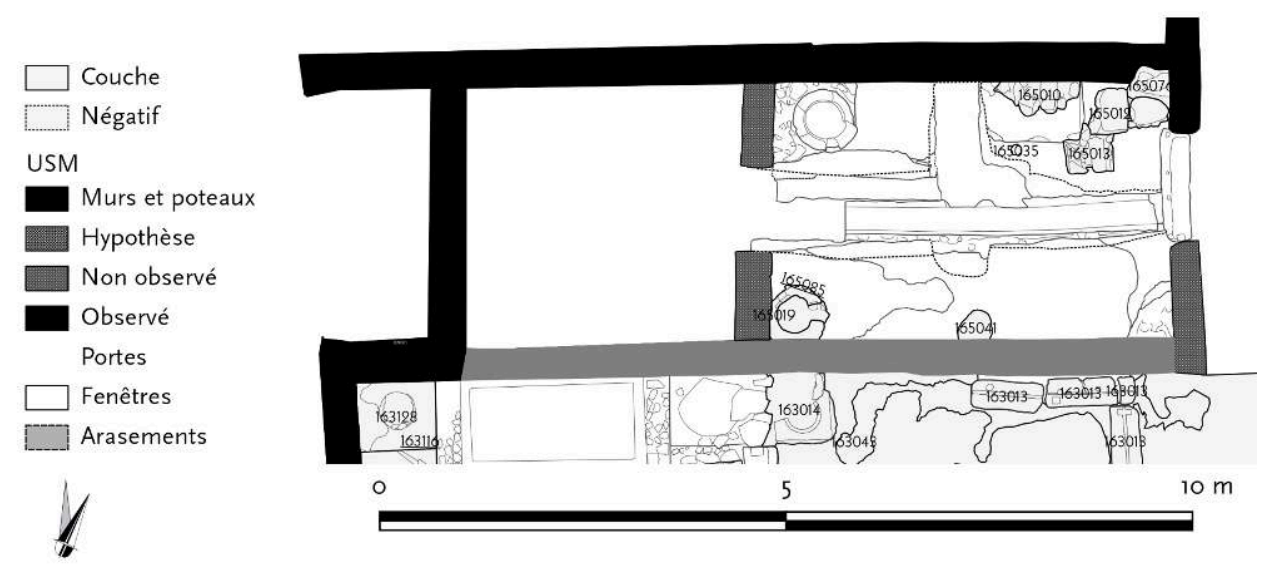

Relevé, dessin : F. Fouriaux / N. Monteix / EFR. @ C CC BY-NC-SA. 
Fig. 41 - Pompéi, VI 16, 5. Relevé photogrammétrique du clibanus mis au jour dans la pièce 1.

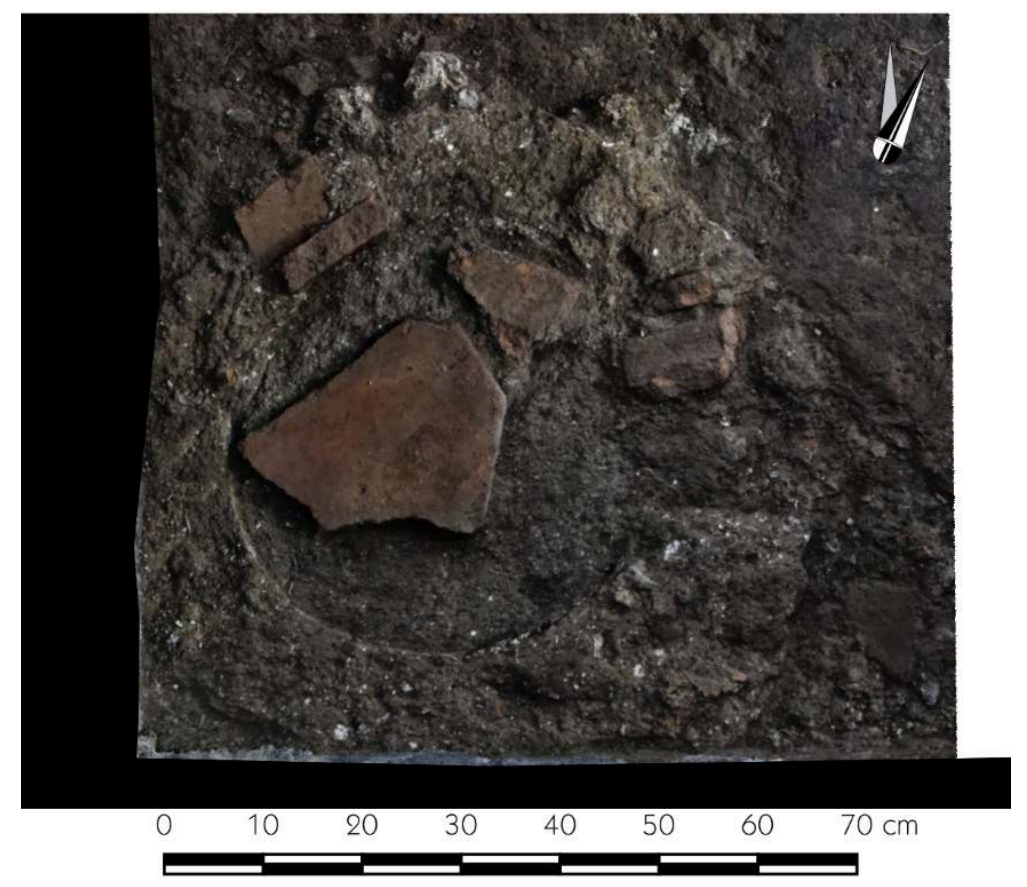

\section{Perspectives}

Au-delà des indispensables compléments de sondages dans l'atelier VI 16, 3-4, au centre de celui-ci, qui permettront en particulier de faire le lien stratigraphique entre les différents secteurs ouverts ces deux dernières années, il faudra tenter de répondre à la question de l'implantation d'une foulerie précoce, peut-être plus réduite, dans la pièce 2 .

37 L'exploration de l'arrière-boutique de VI 16,5 permettra certainement d'affiner la chronologie proposée ici et peut-être d'émettre des hypothèses quant aux activités effectuées dans cet espace pendant les dernières années de la ville.

Il faudra également, dans les deux ensembles, approfondir notre compréhension des variations des systèmes d'alimentation et d'évacuation des eaux (fig. 42). Par-delà les questions touchant à l'alimentation en eau de Pompéi juste avant l'éruption, il faudra tenter de comprendre le mode de remplissage des quatre citernes observées dans ces deux espaces, mais aussi obtenir des réponses sur les systèmes d'évacuation déployés dans les premières phases de fonctionnement de l'atelier textile. 
Fig. 42 - Pompéi, VI 16, 3-4 et VI 16, 5. Évolution des systèmes d'approvisionnement et d'évacuation de l'eau.

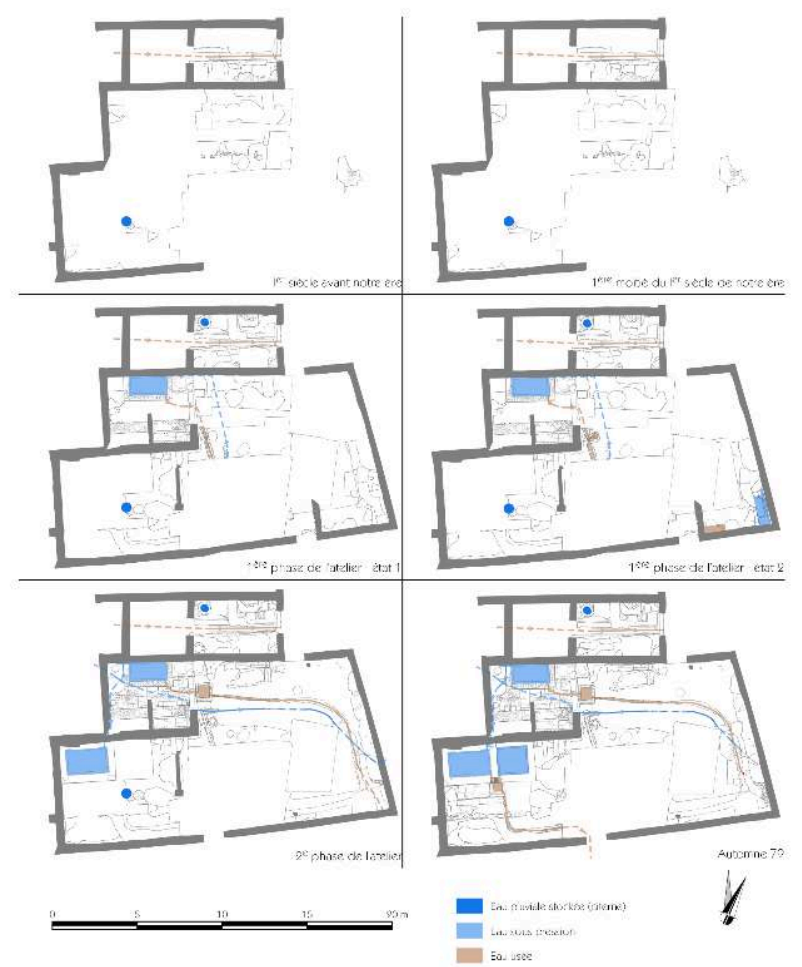

Relevé, dessin : F. Fouriaux / N. Monteix / EFR. ㄷ CC BY-NC-SA.

\section{BIBLIOGRAPHIE}

Dessales 2013 = H. Dessales, Le partage de l'eau : fontaines et distribution hydraulique dans l'habitat urbain de l'Italie romaine, Rome, 2013 (BEFAR, 351).

Flohr 2011 = M. Flohr, Cleaning the Laundries III. Report of the 2008 Campaign, dans FOLD\&R, 214, 2011, p. 1-14.

Maiuri 1931 = A. Maiuri, Pompei. Pozzi e condutture d'acqua nell'antica città. Scoperte di un antico pozzo presso 'Porta Vesuvio', dans NSA, 1931, p. 546-576.

Maiuri 1973 = A. Maiuri, Alla ricerca di Pompei preromana. Saggi stratigrafici, Naples, 1973.

Monteix 2013 = N. Monteix, The apple of discord: fleece-washing in Pompeii's textile economy. A response to M. Flohr, dans Journal of Roman Archaeology, 26, 2013, p. 79-87.

Monteix et al. 2015 = N. Monteix, S. Aho, A. Delvigne-Ryrko, A. Watel, Pompéi, Pistrina, dans Chronique des activités archéologiques de l'École française de Rome, 2015.

Monteix et al. 2019 = N. Monteix, E. Le Quéré,

F. Fouriaux, S. Aho, B. Ephrem, S. Lepetz, E. Proudfoot, C. Autret, Les ateliers au sud-est de la Casa 
degli Amorini Dorati à Pompéi. Foulerie VI 16, 3-4 et foulerie VI 16, 6, dans Chronique des activités archéologiques de l'École française de Rome, 2019.

Nappo 1996 = S.C. Nappo, L'impianto idrico a Pompei nel 79 d.C. Nuovi dati, dans G.C.M. Jansen, N. de Haan (dir.), Cura aquarum in Campania, Leiden, 1996 (BABesch. Supplement, 4), p. 37-45.

Nappo 2002 = S.C. Nappo, L'impianto idrico a Pompei. Documentazione e nuovi dati, dans In binos actus lumina. Rivista di studi e ricerche sull'idraulica antica, 1, 2002, p. 91-108.

Seiler 1992 = F. Seiler, Casa degli Amorini Dorati (VI 16,7.38), Munich, 1992 (Häuser in Pompeji, 5).

Sogliano 1906 = A. Sogliano, Pompei. Relazione degli scavi fatti dal dicembre 1902 a tutto marzo 1905, dans NSA, 1906, p. 345-352.

\section{NOTES}

1. DG-ABAP SERV II 22/03/2018, prot. no0008293-P.

2. L'identification de ces niveaux a été confirmée par M. Robinson (Oxford University) lors d'une visite sur le chantier. Nous le remercions chaleureusement de ses commentaires. Il convient de noter que ces niveaux de paléosols présentent un pendage du sud au nord, soit une inversion par rapport à celui prévalant actuellement.

3. Monteix et al. 2019, § 7 .

4. Seule une fosse (163267) préexistait à ces creusements. Ni sa forme ni le contenu de ses remplissages $(163241,163266)$ ne permettent de l'interpréter de manière claire ou de la rattacher à un moment chronologique précis.

5. Il n'est pas possible pour l'heure de déterminer si l'actuelle porte 3 a été créée/maintenue lors de ces transformations. La prochaine campagne permettra probablement de répondre à cette question si la tuyauterie moderne n'a pas trop perturbé la stratigraphie. Par ailleurs, en l'état actuel de nos connaissances, aucune partition courant du nord au sud de l'atelier n'a été mise au jour à l'est de l'actuelle porte 3 et à l'ouest de la porte 3 bis.

6. Sur ces différents éléments, voir Monteix et al. 2019, § 11-17.

7. Il est probable qu'un étage se développait alors au-dessus de l'emprise de cette pièce. Des traces d'escalier sont conservées dans la paroi méridionale.

8. Monteix et al. 2019, § 14 .

9. Monteix 2013. On soulignera cependant que la fouille de cet atelier amènera à revisiter une partie des vues proposées dans cet article, sans toutefois remettre en question l'interprétation principale de ces ateliers comme laveries de toisons.

10. Sur ces fosses de la partie septentrionale, voir Monteix et al. 2019, § 18.

11. Monteix et al. 2019, § 19-26.

12. Découvert au fond de la canalisation moderne d'adduction en eau, ce trou de poteau était rempli de lapilli au moment de la fouille. Ce remplissage pallie sans difficulté la disparition du sommet du creusement.

13. Un bilan bibliographique est dressé dans Dessales 2013, p. 250-251, sans toutefois prendre en compte la question des multiples séismes et la distinction à apporter entre les dégâts consécutifs au séisme de $62 / 63$ et ceux immédiatement antérieurs à l'éruption. Voir également, pour les données de fouilles les plus récentes, quoique d'exploitation parfois complexe, Nappo 1996 ; Nappo 2002.

14. L'état d'écrasement de l'extrémité du tuyau n'a pas permis de prendre des mesures complètes à l'intérieur.

15. Une pelle en fer a par ailleurs été oubliée dans le comblement de lapilli. 
16. À titre de comparaison, le tuyau 163010, qui alimentait l'atelier et les fontaines de la Casa degli Amorini Dorati, mesurait 3,5 cm de large pour $4 \mathrm{~cm}$ de haut.

17. Maiuri 1931 (= Maiuri 1973, p. 24-27).

18. Comme le remarquait M. Flohr (2011, p. 6-8), les deux bassins ne pouvaient pas être vidés en même temps. Signalons au passage que le système de remplissage du second bassin en exploitant la surverse du premier nous semble hautement conjecturale.

19. Flohr 2011, p. 6.

20. La description de la pièce 1 proposée par A. Sogliano (1906, p. 350) est la suivante : «Il vano n. 5 ha soglia di lava ed aveva imposte di legno nella metà interna dei pilastri angolari. L'ambiente $\mathrm{J}$ al quale dà accesso, ha le pareti affatto disadorne. Addossati alla parte destra della parete settentrionale veggonsi gli avanzi come di un gran poggio in muratura, con due scalini dinanzi (q). A destra di questo stesso e propriamente nell'angolo nord-est pare di vedere gli avanzi di un fusorium. Verso le estremità della stessa parete una bocca di cisterna in lava, circolare ( $p$ ) ». Le terme fusorium est particulièrement peu clair dans ce cadre.

21. En effet, une porte bouchée au fond de la pièce 2 de la boutique VI 16, 6 s'est ouverte à un moment sur le péristyle de la Casa degli Amorini Dorati. Par ailleurs, une seconde porte bouchée a mis en lien pendant un temps les ateliers VI 16, 3-4 et VI 16, 5.

22. Dans la foulerie voisine VI 16,6, les niveaux éruptifs anté-pliniens ont été observés entre $35,61 \mathrm{~m}$ et 34,93 $\mathrm{m}$ à une distance de $8,40 \mathrm{~m}$ vers le nord.

23. Si un léger doute subsiste, rien ne permet pour l'heure de supposer que l'enduit a été refait lors de la remise en fonction de la canalisation au début $\mathrm{du} \mathrm{Xx}^{\mathrm{e}} \mathrm{s}$.

24. Bien que considéré comme une seule unité stratigraphique, le remblai 165056 est en fait constitué d'une série de lentilles d'épaisseurs et de natures variables, déposées dans un unique moment.

25. Seiler 1992, p. 78-81.

26. La cohérence entre les niveaux de sol observés et les élévations conservées rend peu probable l'hypothèse que l'atelier se soit trouvé en VI 16, 5.

27. Si l'intérêt de faire un tel creusement pour rouvrir une porte nous échappe intégralement, la séquence stratigraphique est assurée.

28. Monteix et al. 2015, § 40.

\section{INDEX}

institutions École française de Rome, Université de Rouen (Groupe de recherches en Histoire GRHIS, EA 3831), Institut universitaire de France, en collaboration avec le Parco archeologico di Pompei et avec le soutien du Centre Jean-Bérard (CNRS/EFR, USR 3133), du Centre Camille-Jullian (UMR 7299), d'Ausonius (UMR 5607) et Cogitamus Laboratory.

Mots-clés : Pompéi, atelier, production textile, aménagements hydrauliques, approvisionnement hydraulique, four à pain, métallurgie du fer

Index géographique : Pompéi 


\section{AUTEURS}

\section{NICOLAS MONTEIX}

Institut universitaire de France - nicolas.monteix@univ-rouen.fr

ENORA LE QUÉRÉ

Université de Rouen-Normandie - enora.le-quere@univ-rouen.fr

\section{FRANÇOIS FOURIAUX}

École française de Rome - francois.fouriaux@efrome.it

\section{BRICE EPHREM}

Ausonius, CNRS - ephrembrice@yahoo.fr

JONATHAN DEVOGELAERE

Centre Camille Jullian CNRS/AMU - jonat_dev@hotmail.fr

\section{CAMILLE NOÛS}

Cogitamus Laboratory - camille.nous@cogitamus.fr 